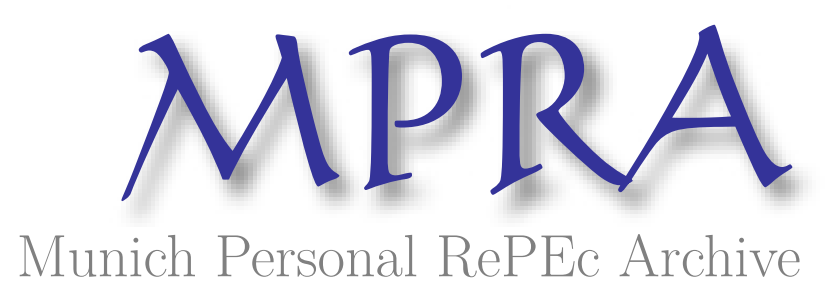

Determinants of Small Business Survival: The Case of Very Small Enterprises of the Traditional Manufacturing Sectors in Brazil

GUIMARÃES BARBOSA, EVALDO

30 June 2016

Online at https://mpra.ub.uni-muenchen.de/72304/

MPRA Paper No. 72304, posted 02 Jul 2016 01:53 UTC 


\title{
DETERMINANTS OF SMALL BUSINESS SURVIVAL: THE CASE OF VERY SMALL ENTERPRISES OF THE TRADITIONAL MANUFACTURING SECTORS IN BRAZIL
}

\author{
Evaldo Guimarães Barbosa*
}

June 2016

\begin{abstract}
This article reports results from an empirical search for the determinants of the very small firms' survival prospects. Research in the area seems to be excessively concentrated in new firms and fails to include measures related to the investment policies and market strategies of the small firms. Making use of information from balance sheets and perceptual data collected through a survey of a small sample of incumbent small manufacturing enterprises of the traditional sectors in Brazil, the Cox proportional hazard model, new variables and new and unconventional model specifications, the study achieves striking results. The many identified determinants of the small businesses' hazard rates concern the financing, working capital and production technology policies, the matching of investment and financing maturities, the market strategies, the characteristics of the entrepreneur, business risk, profitability and the economic climate. Results are suggestive that the small manufacturing enterprises' viability is highly dependent on keeping under control the elements of the running of the businesses whose judicious administration is advocated by the management science. Whether the successful choices are conscious or the corresponding enterprises are selected in the way predicted by the organizational ecology approach remains unsettled.
\end{abstract}

Keywords: Small firms; Business survival determinants; Business strategies; Cox regression

\section{INTRODUCTION}

Studies that aim at identifying the determinants of business failure are found in six strands of literature, namely, bankruptcy prediction, firm productivity, business demographics, organizational ecology, personality traits and self-employment studies. In all these fields, significant progress has been made in such a search in the last two and a half decades. This has been possible in face of the coming into existence and dissemination of internet, which has eased exchange of experience between authors, developments in econometrics concerning analysis of panel data, routinely computation of the correspondent statistics by standard statistics and econometrics computer packages, and increasing access by researchers to public datasets in many countries of the world, being exception the developing countries.

However, further real breakthroughs will become only possible if researchers start going beyond the use of publicly available information found on extensive data-bases or in annual

*BARBOSA is a retired Tax Officer at the Federal Tax Secretariat in Belo Horizonte City, Brazil. He was formerly an Assistant Professor of Finance at the Federal University of Viçosa. He worked also for enterprises, such as Petróleo Brasileiro S/A. He used to be a Consultant to SMEs in the former governmental Brazilian Center to Support Small and Medium Enterprises. Today, he is an independent researcher, writer and consultant in the small business field.

E-mail: evaldogb@yahoo.com.br 
reports and taking the initiative to collect data directly from the small firms, to include matters that most owner-managers might regard as privileged information (De Jong and Van Dijk, 1998; Romano and Others, 2000).

To take this step, researchers will have to overcome prejudices that lead them to prefer public databases to field surveys. One such prejudice concerns perceptual information. Some allege that simply asking views can hardly be considered as hard proof since one can imagine that managers have an incentive to overstate their problems (Wagenvoort and Hurst, 1999) and others criticize the survey approach because it measures beliefs rather than actions - the approach implicitly assumes that managers' beliefs reflect reality (Frank and Goyal, 2007). Besides, there is the widespread belief that the very small firms' balance sheets and profit and loss statements cannot be taken seriously for whatever they are intended to be used. Technical people believe that, for some reasons, mainly fiscal, they are forged in such a way and extent that if compared with one another no pattern other than that of randomness would result. For sure, it is not very difficult to appoint one or another study that, having made use of perceptual information, seems to have achieved almost nothing in terms of findings. However, it is neither very difficult to appoint studies that, having made use of perceptual, either interview or questionnaire, data, have shed light on some questions related to the running of SMEs and, specifically, small firms. One problem with the prejudice is that the blame for not finding relationships is put only on the interviewee or the respondent, but in truth the problem might reside in many other phases of the research effort.

Another feature of surveys that makes them unacceptable to most types of audience is small sample size, apparently almost inevitable because in-depth surveys involve expensive and time-consuming processes and badly depend on voluntary cooperation by the investigated firms.

However, the above rejection is not exempted from opposition. Brophy and Shulman (1992) affirmed that there existed incentives for small-sample studies, basing their statement on two pieces of evidence. The first was that promising new publishing directions for finance research seemed imminent for the 1990s and that three prestigious academic journals were already encouraging researchers to spend their efforts on single case or clinical studies. The second was that the change in publishing policy occurred as a result of two conceptual advancements. One of them, known as "noise", came to existence out of a criticism of rigorous statistical analyses of information provided by large financial databases, which, although believed to be highly reliable, seemed to have serious pitfalls. Even though a long time has passed since Brophy and Shulman's statements have been made, the review of literature carried out in the present study has not observed any actual change in research orientation as to acceptance of small-sample studies. The same cult dedicated to the big sample size that has always existed seems to pervade studies of business survival in the SME field. Some studies deal with huge populations and amazingly spare time calculating and reporting statistical significance, whereas appraising economic significance and checking for misspecification errors seem to be the actually necessary actions.

On the other hand, the nature of the small firms as opposed to that of big businesses seems to be more suited to interview, survey methodology. According to Barton and Matthews (1989), concerning the risk propensities and goals of top management, subordinates in small, entrepreneurial firms tend to adopt the entrepreneur's decisions uncritically, making it likely that only the entrepreneur's attitudes need to be measured to assess the attitudes of management overall. Still according to them, this contrasts with the case in large firms, where the collective attitudes of the dominant coalition must be assessed.

Every effort has been made to ensure both that the present research would not become "impregnated" by the alleged ills of a small sample and perceptual survey data and that it would 


\section{DETERMINANTS OF SMALL BUSINESS SURVIVAL}

benefit the most from the postulated advantages of such a methodology, in all main operational steps of the investigation, namely, research design, data collection and data analysis. It is with this strong conviction that this piece of research adds to knowledge, first, by introducing into the analysis new variables, whose respective data collection is made possible only via perceptual and survey approaches, such as measures of competitive strategy. Second, by using different methodologies, characterized by the combination of balance sheet with interview data, extensive use of non-linear relationships and introduction of powers other than the unit and the square in the U-shaped models, unconventional to the field but mirrored in research in the medical area.

The achievements of the present study are surprisingly numberless and diversified. First, the degree of explanatory power achieved in the analyses is very high for all standards. Statistical significance is also generally very high. Many determinants of the small businesses' hazard rates are identified. The many identified determinants of the small businesses' hazard rates concern the financing, working capital and production technology policies, the matching of investment and financing maturities, the market strategies, the characteristics of the entrepreneur, business risk, profitability and the economic climate. Results are suggestive that the small manufacturing enterprises' viability is highly dependent on keeping under control the elements of the running of the businesses whose judicious administration is advocated by the management science.

In Section 2, a description of the theoretical arguments advanced in the related literature for the postulation of each of the factors as determinants of the small firm's survival prospects is presented. Section 3 deals with the methodological aspects of the research. Section 4 reveals the determinants of small business survival that come out as such from the analyses. The results are confronted with the theoretical arguments raised in Section 2 and with findings from previous works. Section 5 concludes by summarizing the overall results of the research effort and by addressing main implications for theory, policy making and small business support, and for the management of the very small manufacturing enterprises. Of course, the traditional issues of limitations of the present and suggestions for future enquiries are addressed also in this last section.

\section{LITERATURE REVIEW}

Empirical research on the small firms' survival determinants has up till now accumulated a myriad of postulated factors. Thus, reviewing this very wide literature is not possible in view of space restrictions. Reviewing only the factors studied in the research from which this paper originates is already impossible in face of this space constraint. The solution, then, is restricting the review only to the concepts whose operationalizations ended up making part of the final model that is the main result reported in this article.

\section{$\underline{\text { LIQUIDITY }}$}

López-García and Puente (2006) say that one argument that has been put forward is that liquidity constraints force start-ups to enter small and that this initial under investment would impact negatively on the firm's survival probabilities. Van Praag and Others (2005) argue that financial capital constraints may prevent entrepreneurs from creating buffers against random shocks, thereby affecting the timing of investments negatively and having an impact on their firms' survival probabilities.

\section{FINANCIAL LEVERAGE}




\section{EVALDO GUIMARÃES BARBOSA}

Three reasons are suggested in the related literature to postulate a negative impact of financial leverage upon small business survival. First, because increasing debt leads to increased debt service payments for the firm and because there is always the possibility of happening random shocks to profits, higher debt levels increase the number of states of the world where the firm may not meet its debt obligations, so increasing the probability of bankruptcy. Second, high debt firms may take on riskier investment projects because the firm gains if the risks succeed but the creditors lose if they fail. However, there is a greater probability of happening bad states with risky investments, which causes a negative relationship between financial leverage and firm survival. Third and last, there is a predation argument, according to which highly leveraged firms are subject to predation by low leveraged rivals that have access to financial funds. Predation by rivals increases the chances a firm cannot meet its debt obligations in a certain period, increasing its probability to go bankrupt.

\section{PERFORMANCE}

Mata and Portugal (2002) remind that basic economic theory says that firms exit when they incur losses and stay in markets when they are profitable. Pérez and Others (2004) find room to add on to this basic postulate. According to them, high firm profitability can be a signal of both efficiency and market power. If higher profitability is related to higher efficiency, the higher the productivity the higher the survival prospects. If the origin of high profitability is market power, longer lifetimes are expected for firms that are more profitable. That is, profits may provide the necessary resources to develop firm specific assets through innovation and advertising that may ease firm survival.

\section{WORKING CAPITAL}

There is no rationale put forward in the empirical research literature for a postulated link between working capital and small business survival. However, textbooks in finance go at length on the importance of working capital management for the profitability of the firm. As profitability is advocated as vital for longevity so should judicious management of investment in cash balances, inventories and accounts receivables. Theoretical models in this literature present relationships between elements of working capital and costs that resemble asymmetric U-shaped curves. These are models of economic purchasing batch, economic production batch, and optimal credit and collection policies (Van Horne, 1977).

\section{CAPITAL INTENSITY}

Grossi and Gozzi (2006) suggest that the average industry capital intensity is a measure of the extent of scale economies in it and that, therefore, firms increasing their capital intensity are expected to have a higher chance of survival given the scale of their respective industry. LópezGarcía and Puente (2006) affirm that the share variable costs represent in relation to total cost is inversely determined by capital intensity and, consequently, if there is a negative shock by which prices go down, for example, less capital-intensive firms will exit the market first. According to Shiferaw (2009), more capital per person could enhance labor productivity and reduce the hazard of failure. This is a view espoused by theories of industrial evolution that relate firm survival to investment in productivity-enhancing activities (Pakes and Ericson, 1998).

There are also arguments in favor of a negative association between capital intensity and business survival. According to Shiferaw (2009), standard trade theory claims that capitalintensive industries in economies abundantly endowed with labor would contract or even disappear unless they are protected. 


\section{$\underline{\text { STRATEGY }}$}

Diversification is said to impact positively business survival probability because it reduces the company's variance of earnings. However, for small firms the arguments favor a posited negative relationship, grounded on the ideas that small firms' economic viability depends on finding niche markets to cater for through specialization and concentration of efforts, while avoiding dispersing scarce resources out of the primary line of business on areas that are not known nor well understood yet by the enterprise.

\section{BUSINESS RISK}

There is little about a rationale in the literature on business survival that links it to business risk. However, the capital structure literature itself deals with this link when discussing the relationship between business risk and capital structure. This link can be taken from the statement common to capital structure literature that business risk has a negative impact upon financial leverage because too much risk means most of the time many more states of the world in which cash flows go too down in such a way that is impossible to pay for the service of debt. On top of debt repayments can be added payments to workers, suppliers and governments. Failure to pay for these obligations may mean that the firm will go bankrupt.

\section{CHARACTERISTICS OF THE ENTREPRENEUR}

Many characteristics of the entrepreneur are postulated as having an impact on the survival chances of his/her small firm. Personality traits are said to be among these impactive characteristics. The entrepreneur's risk attitude is a much researched one.

According to Caliendo and Others (2010), psychological research argues that entrepreneurs should take neither the highest nor the lowest possible but instead "well-calculated" risks to become successful. They cite Chell and Others (1991), who maintain that there should be a nonlinear relation-more specifically, an inverse U-shaped relation-between risk attitudes and entrepreneurial survival, where low risk attitudes characterize more risk averse and high risk attitudes indicate less risk averse persons.

\section{ECONOMIC CONDITIONS}

Buehler and Others (2005) argue that the general business climate, measured by the number of bankruptcies in the previous year, raises through 'chain effects' the propensity to exit. Also that fluctuation in the external value of the Swiss currency influences the exits of firms disparately, subject to their export activity, once an increase in the external value of the Swiss currency deteriorates the competitiveness of Swiss firms on foreign markets, and increases the competitiveness of foreign firms on domestic markets. In the words of Farinha (2005), according to the standard approach, during recessions, the contraction of aggregate demand broadly affects all firms' sales and profits and can lead some of them to failure. However, in the empirical literature, some results suggest that this effect is less important than the aggregate approach predicts. A more recent approach that emphasizes firm heterogeneity and adjustment costs (e.g. sunk costs) asserts that recessions induce a restructuring process (characterized by labor lay-off and productivity increases). It is also plausible that under recessions the competitive pressure exerted upon established units by newcomers is alleviated. 
Others concepts contemplated in the review of literature in the original research included asset structure, productivity, size, growth, age of the firm, industry, aversion to sharing control, other owner's characteristics, capital share concentration, legal form, financial constraints and creditworthiness.

\section{METHODOLOGY}

\subsection{SOURCES OF DATA}

Data used in the study have been originally gathered to investigate the determinants of the small firms' capital structure. They were collected in 1992. Information on exit was recorded year-by-year up to 2005 . The original data were collected from two sources. First, from year-end balance sheets provided by the very small firms for the years 1.986, 1.987, 1.988, 1.989, 1990 and 1.991. Second, from personal interviewing carried out through a structured interview schedule. Data for 75 five enterprises were collected for the original work. Data for 61 firms correspond to the availability for the version of the research being reported. The difference is due to incompleteness of balance sheet information. The duration of the business was calculated in number of days since the end of 1992 up to time when the enterprise stopped paying taxes calculated on the basis of monthly sales or salaries paid to workers or December 31, 2005, the last day of the follow-up.

The investigated small firms were randomly selected from directories run by trade associations of the three manufacturing sectors studied, namely, the furniture, the food and the clothing industries. The sample was also limited to enterprises located in the Cities of Belo Horizonte and Contagem. These are the two biggest cities in the State of Minas Gerais, being Belo Horizonte the Capital of the State. The corresponding area is a most important industrial one in the whole of Brazil.

It was decided at the time of research design that only enterprises with more than 15 and fewer than 200 employees would be included in the original work. Small firms with less than 15 employees would be excluded because they hardly produce profit and loss accounts and balance sheets on a regular basis and because these accounting reporting instruments were crucial for the kind of research being undertaken. Enterprises with more than 200 employees would be excluded because they are not considered small by most institutions working in the field of support to small firms. At the time of data collection, small firms of any size were excluded, if found out that they were not totally independent of other enterprises, to harmonize the research with a widely accepted qualitative criterion of firm smallness. An independent small firm is understood here to be one that is not part of a bigger enterprise and whose owner is totally free to make his/her own decisions. Because of the qualitative independence criterion, only enterprises with less than 150 employees ended up being selected for both the original work and the version being reported.

\subsection{OPERATIONAL DEFINITIONS}

All balance sheet measures presented below were calculated for a time span of one to six years, depending on the availability of data, which is for three years for the majority of cases.

\section{$\underline{\text { LIQUIDITY }}$}


The concept of Liquidity is operationalized by the variable Net Working Capital, which is understood as the part of equity plus medium- and long-term debt in excess of long-term assets, which in turn encompass the amount of fixed assets and other long-term investments of the firm. Net Working Capital is defined as a proportion to isolate for the sheer effects of size, as follows:

$$
\text { NET WORKING CAPITAL }=\frac{(\text { Equity }+ \text { Medium }- \text { and Long }- \text { term Debt }- \text { Long }- \text { term Assets })}{\text { Current Assets }} \times 100 \text {. }
$$

Medium- and Long-term debt incorporates up-to-one year repayable bank loans plus beyond-one-year repayable external loans and other liabilities.

\section{FINANCIAL LEVERAGE}

The concept of Financial Leverage is operationalized by two variables, namely, Total Financial Leverage and Medium- and Long-term Financial Leverage. For the sake of precision,

$$
\text { FINANCIAL LEVERAGE }=\frac{\text { Total Debt }}{\text { Total Assets }}
$$

Some work was done before the calculation of the values for financial leverage so that the balance sheets first mirrored the perspective of finance instead of that of accounting. Among the many adjustments, owners' loans to the firm were treated as equity. It seems more appropriate to consider them transitory equity than debt. It is assumed that owners' loans are not comparable to actual debt financing when creditors' claims and rights are considered. Thus, incorporating owners' loans to the firm back to net worth seems a desirable correction, at least as far as the computation of meaningful small firm debt ratios is the objective.

Medium- and long-term financial leverage is the sum of up-to-one year bank loans plus long-term bank loans and other long-term liabilities repayable beyond one year, such as hire purchase and leasing obligations.

\section{PERFORMANCE}

Profitability is the variable that operationalizes the concept of Performance. It was constructed from an interview question asking the entrepreneur to rank from alternatives given in the schedule the relative importance of each source of funding. Therefore, for the answer that retained profits were the most important of all sources was given value five for the corresponding firm in the scale of Profitability. For the answer that profits were the second most important source of funding was given the value four for the corresponding firm in the scale of Profitability. The procedure went on like that and the lowest value, that is, zero was given to an enterprise for which the answer was that profits were not among the five most important sources of funding.

\section{WORKING CAPITAL}

Working Capital is measured by a variable named Operational Cycle. Operational Cycle herein means the total length of time it takes money to become money again from accounts receivable, once money first became raw-material, then work-in-process, after that finished goods and last accounts receivable. 
Operational Cycle was then measured by summing the answers by the entrepreneurs to the interview schedule questions on the average ages of inventories (raw material, semi-processed and finished products) and accounts receivable for their enterprises.

\section{CAPITAL INTENSITY}

This concept is operationalized through two variables aiming to capture different effects of the firm's fixed assets structure. The first one, that is, Automation Degree has the objective of measuring the degree of substitution of machines for labor. The interviewed entrepreneurs were asked where, on a scale of AUTOMATION ranging from one to five, their enterprises would be placed in comparison to their competitors or other enterprises in the same industry activity branch and only in Brazil. If difficulties in answering the question were faced, the interviewees were helped with a written guidance. This written guidance is that the "LEAST AUTOMATED" enterprise (that is, the one that has the greatest number of production activities carried out by use of hand tools or manual machines or even totally manually) that is known of in the enterprise's business activity branch is given code "one" on the scale. The "MOST AUTOMATED" enterprise (that is, the one that has the greatest number of production activities performed by machines) that is known of in the enterprise's business activity branch is given code "five" on the scale. Enterprises in "INTERMEDIATE STAGES" are given codes "two", "three" and "four" depending on whether they are nearer, in technological terms, the "LEAST AUTOMATED", on the one hand, or the "MOST AUTOMATED", on the other hand.

The second variable, namely, Machinery/Fixed Assets Ratio was calculated by dividing plant and equipment into the sum of all the items making up fixed assets, which basically include, in the studied small manufacturing companies, land, buildings, plant and equipment, vehicles and furniture. The selection of this measure is inspired by the statement by Binks (1979) that for a small firm a higher proportion of fixed assets does not mean higher capacity to collateralize debt, since very small firms are urged to start acquiring plant and equipment well before they are able to begin buying property, and plant and equipment are often considered unacceptable as viable security. Thus, this variable has different meanings, depending where in the scale a specific small firm is located. Towards the end of the scale, it means that all investment in fixed assets is made in plant and equipment, what can mean that the enterprise is highly capital intensive. Being on the other extreme of the scale does not mean that the enterprise is not capital intensive, but that most of its investment in fixed assets is in land and buildings. Last, being in the middle of the scale might mean that the small enterprise has a lot of money invested in vehicles and apparels for keeping stock or for the transportation of finished goods.

\section{$\underline{\text { STRATEGY }}$}

There are four operationalizations for the concept of Strategy. There is first the variable Corporate Diversification, which corresponds to answers the interviewees gave to a question directly asked. They were asked for the percentage of sales turnover stemming from activities other than the small enterprise's primary manufacturing activity. As an example, one answered that the primary manufacturing activity was children's clothing, but that $5 \%$ of sales would come from the production of school bags in the beginning of the school year. Another one answered that the primary manufacturing activity was clothing, but that $5 \%$ of sales would come from the laundry business. The highest percentages, around 70\%, came from enterprises that, having declared manufacturing as the primary activity, operated as well as retailers or wholesalers of the raw-materials of the finished products. 
The second operationalization of Strategy is Market Concentration. The interviewed owner-manager was asked to ascertain the percentage of the firm's sales turnover that went to different markets in Brazil. The alternative markets were the metropolitan area of the State Capital of Minas Gerais, the State interior, the State of São Paulo, the States of Rio de Janeiro and Espírito Santo taken together, the South, North, Northeast and Center-west Regions of Brazil. Then, altogether, the number of geographic markets catered for by the small manufacturing firms was eight.

The degree of Market Concentration was then computed by the formula below:

$$
\text { Market concentration }=\frac{\left(X_{1}^{2}+X_{2}^{2}+\ldots+X_{n}^{2}\right) n-10,000}{100(n-1)}
$$

Where:

a) $0<$ Market concentration $<100$

b) $X_{1}, X_{2}, X_{3}, \ldots, X_{n}=$ Proportion of total sales that goes to markets $1,2,3, \ldots, n$, respectively

c) $X_{1}+X_{2}+\ldots+X_{n}=100$

d) $n=$ Number of markets that are catered for by the small firms

Third, there is Client Concentration. In another different interview question the interviewed owner-manager was asked to ascertain the percentage of the firm's sales turnover that went to different clients. The alternative types were big enterprises, small- and medium-sized enterprises taken together, wholesalers, retailers, consumers, government and others, including in this last category "sacoleiras", women who sell from home to home mainly clothes to friends preferably. Then, altogether, the number of client types catered for by the small manufacturing firms was seven.

The degree of Client Concentration was then computed through the same formula as above, just by substituting client for market.

In the formula, $n$ takes the values of eight and seven for the Market Concentration and the Client Concentration indexes, respectively.

The fourth and last operationalization of Strategy is Sales Concentration in Big Clients. This variable corresponds to the percentage of sales turnover that went to big firms, wholesalers and government altogether.

\section{BUSINESS RISK}

The interview schedule incorporated some questions for measuring some important concepts. This was the case of the variable Sales Unpredictability, which was devised to measure business risk. Specifically, the interview question upon which the measure sales unpredictability was constructed asked the entrepreneur to rank from alternatives given in the schedule the relative importance of each kind of difficulty faced by him/her in running his/her small firm. Therefore, for the answer that coping with unexpected shocks to demand was not amongst the three most important difficulties was given value zero for the corresponding firm in the scale of the variable Sales Unpredictability. For the answer that overcoming an unforeseeable demand shock was only the third most important difficulty was given value one. If the answer was that it was the second most important, then the variable took value three. Finally, for the answer that coping with 
unexpected shocks to demand was the most important difficulty of all was given value six for the corresponding firm in the scale of the variable Sales Unpredictability.

\section{CHARACTERISTICS OF THE ENTREPRENEUR}

Only one variable operationalizes the concept Characteristics of the Entrepreneur, namely, Entrepreneur's Risk Tolerance.

The time when the interviews were carried out was characterized by very high inflation rates, ambiguous economic set up, examination by the Brazilian Congress of the Country's President Impeachment and widespread fear in view of recurring governmental recessionary economic packages. Entrepreneurs were asked how they thought the market should be exploited in this all-unfavorable social and economic atmosphere. Specifically, they were asked to position themselves on a scale ranging from one to five, corresponding one to maximum caution and five to maximum entrepreneurial riskiness. Taking these values directly was the way Entrepreneur's Risk Tolerance was measured in this work.

Verheul and Thurik (2001) measured risk attitude in a self-perceptive five-interval scale very similar to the one used in this work. The mean response was 3.81, which is much higher than the mean of 2.51 obtained in this work, according to Appendix I. However, these authors worked with start-ups, which are supposed to involve a higher level of tolerance to risk than in a sample of incumbent firms. In the De Mel and Others (2010)'s study, SMEs owners of incumbent small firms averaged 2.8, after converting theirs into the scale used by this work. The mean score in the German Socioeconomic Panel, after recoding its values into the values of the five-interval scale, is 1.94 (De Mel and Others, 2009). These figures are consistent with the idea that common people are the least tolerant to risk, owners of incumbent firms are more tolerant than common people but are less tolerant than start-up entrepreneurs, suggesting that the method used in this research correctly assessed the interviewed entrepreneurs' risk attitude.

\section{ECONOMIC CONDITIONS}

Two variables are used to operationalize Economic Conditions: The 3-year-lagged GDP Growth Rate and The 1998 Year Dummy.

Estimates of the effects of general economic conditions were obtained by use of many economic indicators, like gross domestic product and rate of unemployment. Because GDP showed to be highly collinear with time, troubling regression estimation, the GDP growth rate was used instead. For the period referring to the follow-up on survivorship, The 3-year-lagged GDP Growth Rate was used. Data were obtained from IBGE, under the heading "Produto Interno Bruto (PIB) - variação em volume (\%)".

Binary variables were used to estimate the effects of economic conditions in each of the years of the follow-up on survivorship. Results are reported in the tables on only the one that is statistically significant in the hazard rate regression analyses. The 1998 Year Dummy is set equal to one for failures taking place in the year 1998 and zero otherwise.

\section{$\underline{\text { OTHERS }}$}

Many other concept operationalizations were worked with, but, as they do not compose the models shown in the tables below, suffice to mention them. They are short-term financial leverage, asset composition, industry, manufacturing sector performance, type of firm, legal form, 


\section{DETERMINANTS OF SMALL BUSINESS SURVIVAL}

capital share concentration, main owner's gender, main owner's age, labor productivity, total factor productivity, capital/labor ratio, sales variability, total assets, sales turnover, employment , growth in employment, financial constraints, creditworthiness, among others.

\subsection{INSTRUMENT OF ANALYSIS AND WORK METHODOLOGY}

Following a new and strong tendency in the social sciences, the choice of instrument of analysis to be applied to the survival data in this study was for duration models. The variable of interest in duration analysis is the length of time that passes between the moment at which the phenomenon begins and the moment in which either the phenomenon terminates or the measurement is taken, which might occur at a time before the termination of the phenomenon. For this reason, the conventional statistical methods are not seen as adequate for the duration analysis of a process, since they fail to take into account the evolution of the exit risk and its determinants over time and to consider the censor problem in the data.

Out of the various duration models, the Cox proportional hazard was used as the reference one for the empirical analyses, again following the choice of most of the related empirical literature. The Cox proportional hazard model specifies the hazard function $h(t)$ to be the following:

$$
h(t)=h_{O}(t) e^{X b}
$$

where $h(t)$ is the rate at which firms exit at time $t$ given that they have survived in $t-1, h_{0}$ is the baseline hazard function when all the covariates are set to zero, and $\mathrm{X}$ is a vector of firm, industry and economy characteristics postulated to impact on an enterprise's hazard rate.

The dependent variable is the time of exit. Since the exit time of those small manufacturing enterprises that survived until the end of 2005 is not observed (the longitudinal data for the period 1992 to 2005 were used in the analysis), the distribution of the dependent variable is censored at year 2005.

Long (1997) lists some specific, minimum requirements to undertake detailed analysis of duration, most of which this study sample does not match, in special its sample of firms, which is not sufficiently large. Because of this, a more stringent work methodology was designed for the present research to make results more credible. Thus, for the purposeful selection of covariates to make up the final model of the determinants of survival, whose analyses made use of the ML Cox regression, acceptable significance was set to the two-tailed $0.1 \%$ level.

Statistics used for carrying out the various tests in the survival analyses are the traditional ones. These include z-statistics, LR chi2, and the like. However, for assessing the goodness of fit of the hazard rate equations, the rarely used $R_{p}^{2}$ suggested by Hosmer and Lemeshow (1999) was chosen. The great majority of authors do not make use of any measure analogous to $R^{2}$ as a measure of model performance. The reason for this is most probably because the value of the measure would invariably be very low, which is a conclusion made possible by the fact that in most cases it is possible to calculate the figure for the $R_{p}^{2}$ from the information provided by the author. 


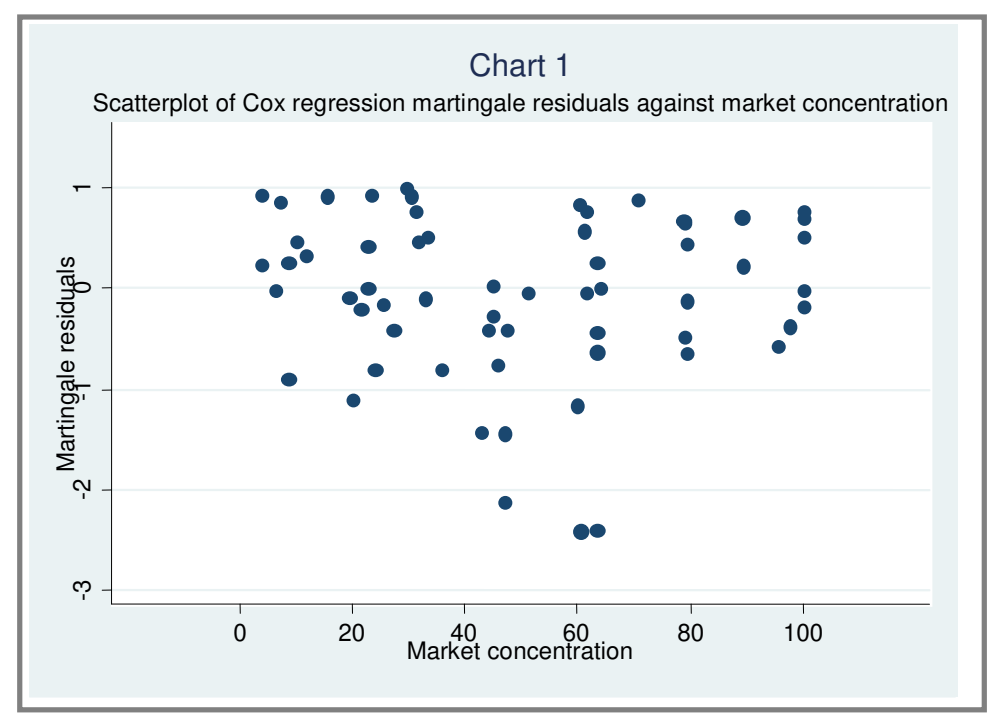

Analysis of residuals was extensively carried out for detection of influential values. The SPSS Dfbeta and $\mathrm{X}^{*}$ Beta were the statistics used for assessing the size of potential undue influence by outliers upon covariate coefficients. For individual covariates, scatterplots like the one shown in Chart 1 were extensively used also for detecting influential outliers and analyzing the reasons for either keeping or dropping them out of the final regression equations. For the whole equation, Chart 2 shows that outliers do not occur in the hazard rate regression analyses.

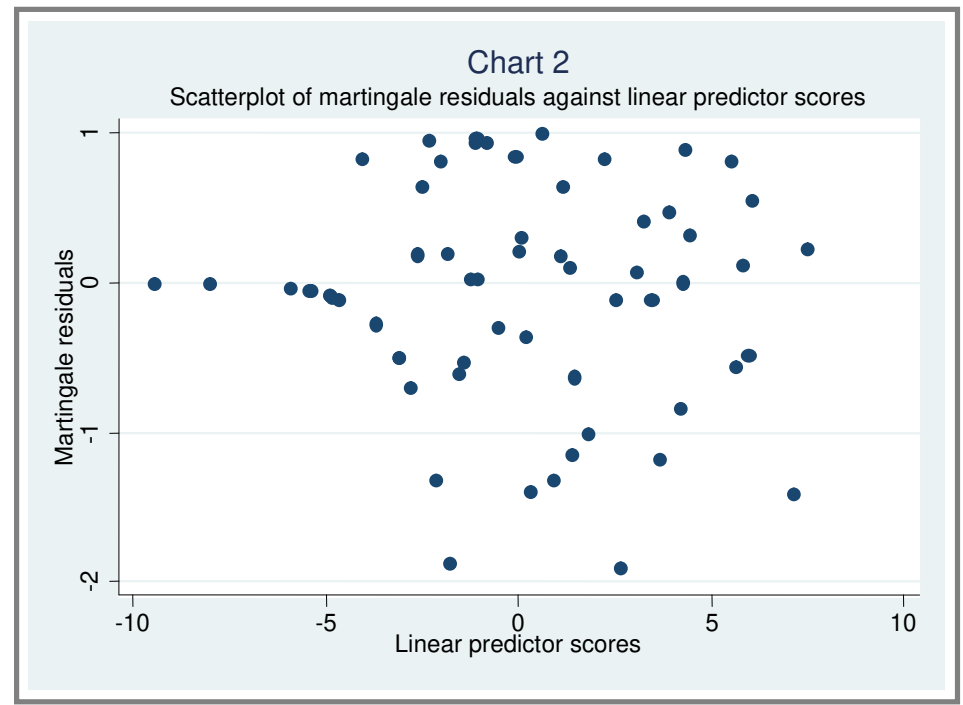

Other features differentiate the analyses that were carried out in this study from those reported in similar previous works. Extensive use of non-linear specifications and powers other than the unit and the square in the U-shaped specifications was made, following the method of fractional polynomials for the purposeful selection of covariates (Hosmer and Lemeshow 1999). Authors use different ways of introducing variables into the regression equations with a view to capturing possible non-linear effects of the covariates. One of these ways might be equivalent to the one utilized in this research (Everett and Watson 1998).

\section{EMPIRICAL RESULTS}


Table I: Determinants of Small Business Survival/Different Specifications and Models

\begin{tabular}{|c|c|c|c|c|c|c|c|c|}
\hline \multirow{4}{*}{$\begin{array}{c}\text { Regressors/Independent } \\
\text { Variables }\end{array}$} & \multicolumn{2}{|c|}{ Main Equation } & \multicolumn{6}{|c|}{ Auxiliary Equations } \\
\hline & \multicolumn{4}{|c|}{$\operatorname{cox}(1)$} & \multirow{2}{*}{\multicolumn{2}{|c|}{ WEIBULL (2) }} & \multirow{2}{*}{\multicolumn{2}{|c|}{ GOMPERTZ (3) }} \\
\hline & \multicolumn{2}{|c|}{ (1a) } & \multicolumn{2}{|c|}{ (1b) } & & & & \\
\hline & -4.69 & $(-4.29)^{\star \star \star}$ & -5.14 & $(-4.58)^{\star \star \star}$ & -3.94 & $(-3.62)^{\star \star \star}$ & -3.79 & $(-4.11)^{\star \star \star}$ \\
\hline Total Financial Leverage & -10.06 & $(-5.25)^{\star \star *}$ & -10.74 & $(-5.43)^{\star \star \star}$ & -8.95 & $(-4.93)^{\star \star \star}$ & -10.29 & $(-5.82)^{\star * *}$ \\
\hline $\begin{array}{l}\text { Medium- and Long-term Financial } \\
\text { Leverage }\end{array}$ & 15.94 & $(4.28)^{\star \star \star}$ & 15.45 & $(3.86)^{\star \star \star}$ & 16.73 & $(5.05)^{\star \star \star}$ & 16.69 & $(5.05)^{\star \star \star}$ \\
\hline Profitability & -0.67 & $(-3.38)^{\star \star \star}$ & -0.76 & $(-3.62)^{\star \star \star}$ & -0.65 & $(-3.46)^{\star \star \star}$ & -0.74 & $(-4.05)^{\star \star \star}$ \\
\hline Operational cycle $e^{1 / 3}$ & -30.10 & $(-4.36)^{\star \star \star}$ & -28.86 & $(-4.21)^{\star \star \star}$ & -29.51 & $(-4.56)^{\star \star \star}$ & -33.47 & $(-4.96)^{\star \star \star}$ \\
\hline Operational cycle $1 / 2$ & 10.35 & $(4.63)^{\star \star \star}$ & 10.13 & $(4.56)^{\star \star \star}$ & 10.01 & $(4.79)^{\star \star \star}$ & 11.53 & $(-5.25)^{\star \star \star}$ \\
\hline Automation degree & -6.80 & $(-5.53)^{\star \star \star}$ & -7.49 & $(-5.53)^{\star \star \star}$ & -6.58 & $(-5.50)^{\star \star \star}$ & -7.10 & $(-6.08)^{\star \star \star}$ \\
\hline Automation degree ${ }^{2}$ & 1.30 & $(5.78)^{\star \star \star}$ & 1.47 & $(5.80)^{\star * \star}$ & 1.26 & $(5.74)^{\star * \star}$ & 1.39 & $(6.48)^{\star \star *}$ \\
\hline Machinery/fixed assets ratio ${ }^{4}$ & -67.59 & $(-4.60)^{\star \star \star}$ & -71.71 & $(-4.71)^{\star \star *}$ & -53.91 & $(-4.72)^{\star \star \star}$ & -68.35 & $(-4.78)^{\star \star \star}$ \\
\hline Machinery/fixed assets ratio ${ }^{5}$ & 77.48 & $(4.94)^{\star \star \star}$ & 81.89 & $(5.01)^{\star \star \star}$ & 62.60 & $(5.17)^{\star \star \star}$ & 78.70 & $(5.19)^{\star \star \star}$ \\
\hline Corporate diversification & -0.03 & $(-3.54)^{\star \star *}$ & 0.03 & $(-3.33)^{\star \star \star}$ & -0.03 & $(-3.31)^{\star \star \star}$ & -0.04 & $(-3.68)^{\star \star \star}$ \\
\hline Market concentration & -0.11 & $(-3.50)^{\star \star *}$ & -0.11 & $(-3.50)^{\star \star \star}$ & -0.09 & $(-2.75)^{\star *}$ & -0.12 & $(-3.79)^{\star \star \star}$ \\
\hline Market concentration ${ }^{2}$ & $1.16 \mathrm{E}-3$ & $(3.52)^{\star \star \star}$ & $1.09 \mathrm{E}-3$ & $(3.18)^{\star \star}$ & $7.29 \mathrm{E}-4$ & $(2.34)^{\star}$ & $1.28 \mathrm{E}-3$ & $(3.88)^{\star \star \star}$ \\
\hline Client concentration & 0.05 & $(4.87)^{\star \star \star}$ & 0.06 & $(5.02)^{\star \star \star}$ & 0.05 & $(4.80)^{\star \star \star}$ & 0.05 & $(5.39)^{\star \star \star}$ \\
\hline Sales concentration in big clients & 0.09 & $(6.28)^{\star * \star}$ & 0.10 & $(6.08)^{\star * \star}$ & 0.08 & $(6.14)^{\star * *}$ & 0.09 & $(6.77)^{\star \star \star}$ \\
\hline Sales unpredictability & 0.46 & $(3.89)^{\star \star \star}$ & 0.92 & $(4.24)^{\star \star \star}$ & 0.58 & $(4.63)^{\star \star \star}$ & 0.53 & $(4.97)^{\star \star \star}$ \\
\hline Entrepreneur's Risk Tolerance & 2.12 & $(6.16)^{\star \star \star}$ & 2.18 & $(6.14)^{\star \star \star}$ & 2.02 & $(6.21)^{\star \star \star}$ & 2.37 & $(7.27)^{\star \star \star}$ \\
\hline 3-year lagged GDP growth rate & -0.38 & $(-3.37)^{\star \star \star}$ & -0.46 & $(-3.60)^{\star \star \star}$ & -0.27 & $(-2.76)^{\star \star}$ & -0.20 & $(-2.15)^{\star}$ \\
\hline 1998 year dummy & 5.49 & $(4.41)^{\star \star \star}$ & 6.12 & $(4.86)^{\star \star \star}$ & 4.32 & $(3.79)^{\star * *}$ & 5.24 & $(4.64)^{\star \star \star}$ \\
\hline $\begin{array}{l}\text { Market concentration X } \\
\text { Operational cycle }\end{array}$ & $-4.35 E-4$ & $(-3.42)^{\star \star *}$ & $-4.50 \mathrm{E}-4$ & $(-3.43)^{\star \star \star}$ & $-2.95 \mathrm{E}-4$ & $(-2.63)^{\star \star}$ & $-4.94 \mathrm{E}-4$ & $(-3.92)^{\star \star \star}$ \\
\hline $\begin{array}{l}\text { Sales concentration in big clients } \\
\mathrm{X} \text { Machinery/fixed assets ratio }\end{array}$ & -0.09 & $(-4.53)^{\star \star \star}$ & -0.09 & $(-4.22)^{\star \star \star}$ & -0.09 & $(-4.78)^{\star \star \star}$ & -0.09 & $(-4.92)^{\star \star \star}$ \\
\hline Sales unpredictability $X$ Time $^{\#}$ & & & $-1.89 \mathrm{E}-4$ & $(-2.74)^{\star \star}$ & & & & \\
\hline Constant & & & & & 26.11 & $(2.89)^{\star \star}$ & 34.84 & $(3.54)^{\star \star \star}$ \\
\hline Shape Parameter & & & & & $0.70^{+}$ & $(5.59)^{\star \star \star}$ & $14.89 \mathrm{E}-4$ & $(5.80)^{\star \star \star}$ \\
\hline$R_{p}^{2}$ & & & & & & & & \\
\hline LR chi2(21/22/21/21) & $11 s$ & $4^{\star \star *}$ & 12 & $5^{\star \star \star}$ & $10 \varepsilon$ & $4^{\star \star *}$ & 132 & $9^{\star \star \star}$ \\
\hline
\end{tabular}

Obs: 1) First values in the main body of the table are coefficient estimates; 2 ) numbers in parentheses are $z$-statistics; 3$)^{*}$, ${ }^{* *}$, and ${ }^{* * *}$ denote statistical significance at the $5 \%, 1 \%$, and $0.1 \%$ levels, respectively; 4) + this number corresponds to In_p; 5) Number of observations (firms): $61 ; 6)$ " denotes a time-varying covariate.

Tables I and II report coefficients and not hazard ratios. Variables with a positive coefficient are associated with an increased hazard rate and a decreased survival time. The reverse is true for variables with a negative sign. Main equation (1a) in Table I reports results from analyses making use of full follow-up period and specifications reaching the highest power to explain the dependent variable. One of the astonishing "good" overall results depicted in Table I that must be stressed is the very high $R_{p}^{2} \mathrm{~s}$ of all regression equations. They frontally contradict some strong opinions that would doubt their happening. One of them is expressed in the words by Fredland and Morris (1976), who argues that the causes of failure cannot be isolated and that "any attempt to do so is, at bottom, a futile exercise." Another pessimistic view is expressed by Frankish and Others (2012), whose words seem to insinuate that models seeking to explain survival/non-survival of small firms are and will always be plagued by weak explanatory power and inconsistency of key explanatory variables. Another result that stands out in the main 


\section{EVALDO GUIMARÃES BARBOSA}

regression equation (1a) is the fact that the coefficients of all covariates reach statistical significance above the $0.1 \%$ level, meeting the standard set for this research effort.

Table II: Determinants of Small Business Survival/Evolution on time

\begin{tabular}{|c|c|c|c|c|c|c|c|c|c|c|}
\hline \multirow{4}{*}{$\begin{array}{c}\begin{array}{c}\text { Regressors/Independent } \\
\text { Variables }\end{array} \\
\text { Net working capital }\end{array}$} & \multicolumn{10}{|c|}{ COX PROPORTIONAL HAZARD MODEL } \\
\hline & \multicolumn{8}{|c|}{ Auxiliary Equations } & \multirow{2}{*}{\multicolumn{2}{|c|}{$\begin{array}{l}\text { Main Equation } \\
\text { Full time span }\end{array}$}} \\
\hline & \multicolumn{2}{|c|}{$1 / 5$ of time span } & \multicolumn{2}{|c|}{$2 / 5$ of time span } & \multicolumn{2}{|c|}{$3 / 5$ of time span } & \multicolumn{2}{|c|}{$4 / 5$ of time span } & & \\
\hline & -12.58 & $(2.02)^{\star}$ & -5.09 & $(3.44)^{\star \star \star}$ & -5.16 & $(4.22)^{\star \star \star}$ & -4.59 & $(3.97)^{\star \star *}$ & -4.69 & $(4.29)^{\star \star \star}$ \\
\hline Total financial leverage & -10.86 & $(1.96)^{\star}$ & -4.11 & $(2.37)^{\star}$ & -9.18 & $1.30)^{\star \star \star}$ & -10.14 & $(4.92)^{\star \star \star}$ & -10.06 & $(5.25)^{\star \star \star}$ \\
\hline $\begin{array}{l}\text { Medium- and long-term } \\
\text { financial leverage }\end{array}$ & 14.78 & $(2.08)^{\star}$ & 13.28 & $(2.99)^{\star *}$ & 14.39 & $(3.53)^{\star * *}$ & 14.84 & $(4.05)^{\star * *}$ & 15.94 & $(4.28)^{\star \star \star}$ \\
\hline Profitability & -0.52 & $(1.31)$ & 0.04 & $(0.22)$ & -0.62 & $(2.75$ & -0.75 & $(3.56)^{\star \star \star}$ & -0.67 & (3.38) \\
\hline Operational cycle ${ }^{1 / 3}$ & -109.95 & $(2.32)^{\star}$ & -32.43 & $(2.94)^{\star \star}$ & -28.40 & $(2.97)^{\star *}$ & -30.11 & $(3.89)^{\star * \star}$ & -30.10 & $(4.36)^{\star \star \star}$ \\
\hline Operationa & 35.82 & $(2.34)^{\star}$ & 10.56 & $(3.02)^{\star \star}$ & 9.99 & $(3.40)^{\star \star \star}$ & 10.49 & $(4.24)^{\star \star \star}$ & 10.35 & $(4.63)^{\star \star \star \star}$ \\
\hline Automation & -13.46 & $(2.63)^{\star *}$ & -6.75 & $(3.96)^{\star \star \star *}$ & -6.31 & $(4.33)^{\star \star *}$ & -5.79 & $(4.28)^{\star \star \star}$ & -6.80 & $(5.53)^{\star \star \star *}$ \\
\hline Automatio & 2.82 & $(2.52)^{\star}$ & 1.27 & $(4.19)^{\star \star \star \star}$ & 1.22 & $(4.6$ & 1.16 & $(4.75)^{\star \star \star}$ & 1.30 & $(5.78)^{\star \star \star}$ \\
\hline $\begin{array}{r}\text { Machinery/fix } \\
\text { ratio } \\
\end{array}$ & -141.65 & $(2.76)^{\star *}$ & -58.28 & $(3.98)^{\star * \star}$ & -58.62 & $(3.81)^{\star \star *}$ & -64.25 & $(4.32)^{\star * *}$ & -67.59 & $(4.60)^{\star \star \star}$ \\
\hline $\begin{array}{r}\text { Machinery/f } \\
\text { rat }\end{array}$ & 163.91 & $(2.76)^{\star *}$ & 64.72 & $(4.15)^{\star \star \star}$ & 67.81 & $(4.18)^{\star \star \star}$ & 74.11 & $(4.68)^{\star \star \star}$ & 77.48 & $(4.94)^{\star \star \star}$ \\
\hline Corporate d & -0.19 & $(1.51)$ & -0.05 & $(2.14)^{\star}$ & -0.04 & $(2.6$ & -0.03 & $(2.6$ & -0.03 & $(3.54)^{\star \star}$ \\
\hline Market conc & -0.08 & $(0.58)$ & 0.04 & $(0.61)$ & -0.05 & $(1.0$ & -0.11 & $(2.97)^{\star \star}$ & -0.11 & $(3.50)^{\star \star \star}$ \\
\hline Market concentration $^{2}$ & $-4.2 \mathrm{E}-5$ & $(0.03)$ & $-7.79 \mathrm{E}-4$ & $(1.15)$ & $7.29 \mathrm{E}-4$ & $(1.77)$ & $1.31 \mathrm{E}-3$ & $(3.89)^{\star \star \star}$ & $1.16 \mathrm{E}-3$ & $(3.52)^{\star \star \star}$ \\
\hline Client concer & 0.09 & $(2.87)^{\star \star}$ & 0.04 & $(3.57)^{\star \star \star *}$ & 0.06 & $(3.94)^{\star \star *}$ & 0.05 & $(4.04)^{\star * \star}$ & 0.05 & $(4.87)^{\star \star \star *}$ \\
\hline $\begin{array}{r}\text { Sales conce } \\
\text { big cli }\end{array}$ & 0.21 & $(2.02)^{\star}$ & 0.08 & $(3.78)^{\star \star \star *}$ & 0.09 & $(5.31)^{\star \star \star}$ & 0.09 & $(5.62)^{\star \star *}$ & 0.09 & $\mid 6.28$ \\
\hline Sales unpr & 2.27 & 97 & 73 & $(3.23)$ & 0.55 & $(3.65)^{\prime}$ & 45 & (3.6 & 0.46 & $(3.8$ \\
\hline $\begin{array}{r}\text { Entreprene } \\
\text { tolera }\end{array}$ & 4.79 & $(2.72)^{\star *}$ & 1.41 & $(3.65)^{\star \star *}$ & 1.85 & $(5.16)^{\star \star \star}$ & 2.09 & $(5.82)^{\star \star *}$ & 2.12 & $(6.16)^{\star \star *}$ \\
\hline $\begin{array}{r}\text { 3-year-lag } \\
\text { growth }\end{array}$ & -1.37 & (1.51) & -0.70 & $(3.89)^{\star \star \star}$ & -0.35 & $(2.46)^{\star}$ & -0.21 & $(1.76)$ & -0.38 & (3.37) \\
\hline 1998 year & n.a. & M.a. & n.a. & n.a. & 5.03 & $(3.60)^{* \star \star}$ & 5.02 & 0.14 & 5.49 & $(4.4$ \\
\hline $\begin{array}{r}\text { Market conc } \\
\text { Operation }\end{array}$ & $-1.03 E-4$ & $(0.19)$ & $-8.08 \mathrm{E}-5$ & $(0.30)$ & $-7.14 \mathrm{E}-4$ & $(2.19)^{\star}$ & $-6.09 \mathrm{E}-4$ & $(3.37)^{\star \star *}$ & $-4.35 \mathrm{E}-4$ & $\mid(3.4 \%$ \\
\hline $\begin{array}{c}\text { Sales concentration in } \\
\text { big clients } X \\
\text { Machinery/fixed assets } \\
\text { ratio } \\
\end{array}$ & -0.20 & $(1.75)$ & -0.09 & $(3.24)^{\star \star}$ & -0.08 & $(3.43)^{\star \star \star}$ & -0.08 & $(3.58)^{\star \star \star}$ & -0.09 & $(4.53)^{\star \star \star \star}$ \\
\hline$R_{p}^{2}$ & \multicolumn{2}{|c|}{0.69} & \multicolumn{2}{|c|}{0.80} & \multicolumn{2}{|c|}{0.83} & \multicolumn{2}{|c|}{0.83} & \multicolumn{2}{|c|}{0.86} \\
\hline LR chi2(20/20/21/21/21) & \multicolumn{2}{|c|}{$71.84^{\star \star *}$} & \multicolumn{2}{|c|}{$99.45^{\star \star *}$} & \multicolumn{2}{|c|}{$107.91^{* * *}$} & \multicolumn{2}{|c|}{$109.09^{* * *}$} & \multicolumn{2}{|c|}{$119.44^{* \star \star}$} \\
\hline Number of events/cases & \multicolumn{2}{|c|}{$16 / 61$} & \multicolumn{2}{|c|}{$29 / 61$} & \multicolumn{2}{|c|}{$37 / 61$} & \multicolumn{2}{|c|}{$41 / 61$} & \multicolumn{2}{|c|}{$46 / 61$} \\
\hline
\end{tabular}

Obs: 1) First values in the main body of the table are coefficient estimates; 2 ) numbers in parentheses are z-statistics in absolute values; 3$)^{*},{ }^{* *}$, and ${ }^{* * *}$ denote statistical significance at the $5 \%, 1 \%$, and $0.1 \%$ levels, respectively; 4 ) ${ }^{*}$ denotes a time-varying covariate.

Auxiliary equation (1b) in Table I presents results for the specification corresponding to the correction for the covariate Sales Unpredictability for which suspicion of violation of the proportionality assumption of the Cox model was strongest. As the interaction term coefficient does not achieve the level of statistical significance set as standard for the survival analyses in this work, there seems to be no reason to conclude that the proportionality assumption implicit in the Cox hazard model was incorrect for the present study. 
The Weibull (2) and the Gompertz (3) specifications are shown in Table I only for comparison. The Weibull model does not seem to be appropriate if the comparison is based on the $R_{p}^{2}$ and the LR chi2. The Gompertz model appears to be a very good fit in that it has the best $R_{p}^{2}$ and LR chi2. However, because the statistical significance of The 3-year lagged GDP Growth Rate coefficient estimate in the Gompertz model does not reach the standard understood to be appropriate for this sample, the Cox proportional hazard model is the reference specification. Consequently, the discussion on the behavior of the individual independent variables in the next Subsection is carried out with respect to the Cox proportional hazard model only.

Table II is shown because of words of caution or criticisms by some authors. Audretsch (1991) suggests that the determinants of new-entrants' survival crucially depend on the length of the period in which survival is measured. Pérez and Others (2004) make the criticism that a shortcoming of empirical studies that have examined entry and survival of new firms is that their findings arise from a short follow-up period. Although the present work deals with incumbents and not new firms, results in Table II do not seem to depend very much on the length of the follow-up period.

Many covariate coefficients in Tables I and II are extremely high. This raises suspicions of numerical problems as complete separation, quasicomplete separation, monotone likelihood, extreme collinearity or the bias that is well known to be characteristic of maximum likelihood estimates when sample size is small. In-depth scrutiny has revealed that none of these is the case (Barbosa, 2009). In the case of The Machinery/Fixed Assets Ratio, because its original values are constrained to lie between zero and one, raising them to the fourth and fifth exponents results in very small transformed values and, consequently, very large covariate coefficients in the hazard rate regression equations. In the case of the coefficients for the variable Operational Cycle, they turn out to be high to compensate for the extremely high baseline hazard that is generated by the fitted function, whose descending segment of the representative curve has a very steep inclination, as can be visualized through Chart 3. There are at least two ways to bring easily the figures to much smaller values (Barbosa, 2009). However, the versions reported are preferred because presentation is easier and interpretation is more straightforward.

\subsection{SPECIFIC RESULTS WITH COVARIATES}

\section{NET WORKING CAPITAL AND FINANCIAL LEVERAGE}

Net Working Capital has a statistically significant negative coefficient in the hazard rate regression equations. Lower amounts or levels of Net Working Capital raise the firm's probability of running into insolvency. This is in line with finance text books teaching (Van Horne 1977) and with theoretical arguments put forward in the small business survival empirical research literature. Such a result is also in line with findings by Wu and Young (2002) and Bunn and Redwood (2003). However, it contradicts Farinha (2005), who found no statistically significant association between both initial and current liquidity and the hazard rate.

As to financial leverage, the effect on the hazard rate is negative for the Total Financial Leverage and positive for the Medium- and Long-term Financial Leverage. The relationships are statistically highly significant and monotonic, but account has to be taken of the fact that the variables Net Working Capital, Total Financial Leverage, Short-term Financial Leverage and Medium- and Long-term Financial Leverage are all related to each other and, as a result, part of the effect of one of them is captured by the other and vice-versa. One way to account for that 
and to get more insight into the results in Table I is to handle algebraically the terms for these financial variables. Thus, taking the reference regression equation (1a) and adding together the three terms for the variables given by the coefficients shown in Table I:

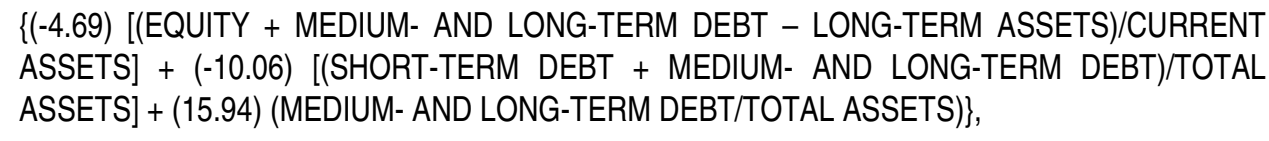

making the correspondent substitutions given the equalities:

$$
\text { EQUITY + MEDIUM- AND LONG-TERM DEBT = TOTAL ASSETS - SHORT TERM DEBT }
$$

and

LONG-TERM ASSETS = TOTAL ASSETS - CURRENT ASSETS,

and carrying on the algebraic operations that are applicable to the case, obtain:

$$
\begin{aligned}
& \{(-4.69)+[(4.69) \text { (TOTAL ASSETS/CURRENT ASSETS) - 10.06] (SHORT-TERM FINANCIAL } \\
& \text { LEVERAGE) + (5.88) (MEDIUM- AND LONG-TERM FINANCIAL LEVERAGE)\}. }
\end{aligned}
$$

The first term (-4.69) is the effect when the enterprise is financed by equity only. When the enterprise has no equity and only medium- and long-term debt the effect will be $(-4.69)+(5.88)=$ (1.19). The term in short-term financial leverage means that its effect depends on the asset structure of the enterprise. If the enterprise's assets are composed of current assets only, then the effect of short-term financial leverage, no matter how high, is negative and maximum. If the enterprise's assets are composed of very few current assets, $1 \%$ for example, then the effect of short-term financial leverage, no matter how low, is positive and very high. The equilibrium, namely, no short-term financial leverage effect, is reached when current assets represent $47 \%$ of total assets, or, in equivalent terms, when long-term assets represent $53 \%$ of total assets.

The relationship represented in the above formula accommodates divergent previous findings. Authors have found monotonic increasing (Fotopoulos and Louri, 2000; Konings and Xavier, 2002; Männasoo, 2008; Bunn and Redwood, 2003; Farinha, 2005; Bottazzi and Others, 2011; Ha, 2013), monotonic decreasing (Bates, 1995; Kang and Others, 2008) and U-shaped functions of the probability of failure on financial leverage (López-García and Puente, 2006; Huynh and Others, 2010). It is possible from equation (8) to generate all these functional forms for short-term financial leverage, medium- and long-term financial leverage and total financial leverage.

\section{PROFITABILITY}

There is not much to say about behavior of the proxy for Performance, namely, Profitability, once results with it are completely in accordance with basic economic theory, which says that firms exit when they incur losses and stay in markets when they are profitable, and with previous studies, which have shown that profitability has a positive impact upon the survival of firms (Grossi and Gozzi, 2006; Fotopoulos and Louri, 2000; Mengistae, 2006; Bellone and Others, 2006; Bottazzi and Others, 2011; Ha 2013). Thus, the widespread belief that what drives an enterprise out of business is lack of cash and not lack of profits does not get much support from results obtained in this work. 


\section{OPERATIONAL CYCLE}

The length of Operational Cycle initially lowers the likelihood of failure, but, as it becomes longer and longer the impact reverses direction and starts to raise such a probability. Chart 3 shows that the maximum reduction on this probability is reached when operational cycle is around 50 days. It also shows that the strength of the impact is not symmetric below and above fifty days, that is, in the first section, the descendent is very steep, but in the second section, the ascendant is very smooth. This non-monotonic result goes in line with models of working capital management in finance text books. On the other hand, it contrasts with the sparse empirical evidence, which deals only with accounts receivable and reports the existence of a monotonic

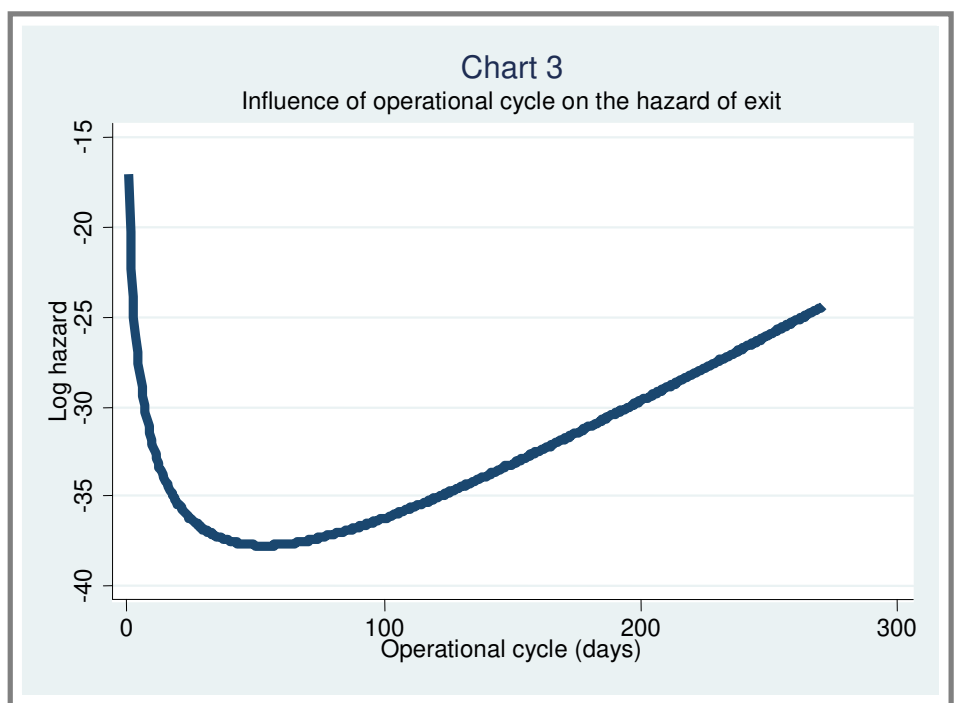

positive relationship between trade credit extended over total assets and the probability of exit in new firms (Farinha 2005). However, the corresponding author does not inform whether a binomial fitting has been tried.

\section{AUTOMATION DEGREE}

This variable has a statistically highly significant impact upon the hazard of exit that is not monotonic. The relationship has a perfect symmetric U shape. This contrasts with the numerous results in the literature that are either a positive impact (Bławat and Others, 2001; Frazer, 2005; Söderbom and Others, 2006; Taymaz and Ozler, 2007) or a negative impact (Doms and Others, 1995; Grossi and Gozzi, 2006; Harris and Li, 2010) upon the hazard rate, or even no relationship (Konings and Xavier, 2002; Shiferaw, 2009; Ha, 2013; Fernandes and Paunov, 2015), being that most of the works that found a negative impact have not worked with a genuine small firm sample. In no case, authors inform whether or not they have tried to fit a binomial specification for their measure of capital intensity. Such inconsistency deserves further treatment in the near future.

\section{MACHINERY/FIXED ASSETS RATIO}

Chart 4 shows the impact of this explanatory variable upon the hazard of exit throughout its entire scale. It should be read backwards. Excessive concentration of fixed investment on plant and equipment raises the probability of exit. As the small manufacturing firm starts to buy other types of fixed assets, as for example, vehicles, the hazard of exit falls to a minimum. With these new fixed assets becoming an increasing portion of total fixed investment, the trajectory of the effect is reversed and The Machinery/Fixed Assets Ratio decreases survivorship. But, this last movement is gentle, so that the impact on the hazard of exit stabilizes as the company starts 
buying land and buildings, probably by virtue of the collateral role played by this last kind of fixed asset.

Controlling for The Machinery/Fixed Assets Ratio amazingly increases the quality of results pertaining to all the other individual effects. To have a better idea, the introduction of The Machinery/Fixed Assets Ratio and of its interaction term into regression equation (1a) raises the LR chi2 from 54.54 to the reported 119.44 in Table I. Astonishingly, this is more than a doubling enhancing effect. This signalizes that it is a highly important covariate and that its absence from the survival analyses is a major source of model-specification error.

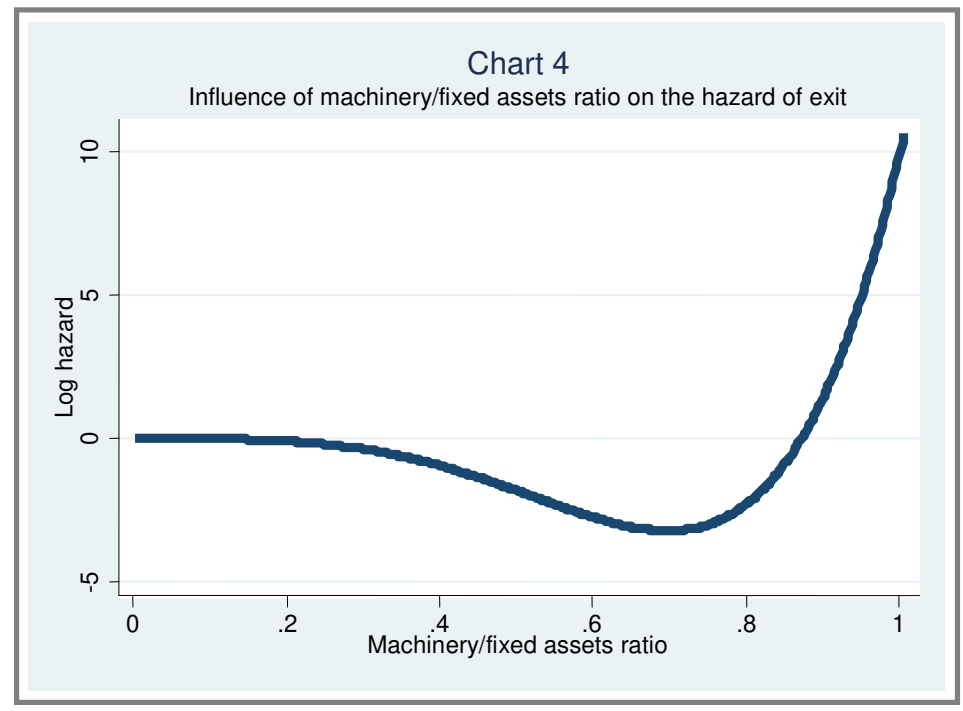

\section{CORPORATE DIVERSIFICATION}

Corporate Diversification is without doubt an important determinant of survival. More diversified small manufacturing firms show a lower probability of failure. This result is totally at odds with the numerous theoretical arguments that favor a negative relationship between corporate diversification and survival, as seen in the Section on review of literature. These arguments are built upon the basic idea that what is good for large enterprises might be bad for the small ones. Nevertheless, it is in perfect accordance with a reasoning that follows from the trade-off model that diversification lowers variance of earnings and consequently raises chances of survival. There is only one previous study that worked with corporate diversification (Fotopoulos and Louri, 2000), with which the present one is in disagreement, once it reaches diametrically opposite conclusions. However, while the present work deals with established small manufacturing enterprises, the other one studied new firms, and perhaps corporate diversification may not be useful for start-ups.

\section{MARKET CONCENTRATION}

The way Market Concentration is related to the hazard of exit seems to make much sense. The descending part of the relationship seems to signalize the cost advantages of concentration, which would surpass up to the minimum of the curve its risk disadvantages. The ascending part of the curve would mean the reverse, that is, the risk disadvantages of concentration surpasses its cost advantages, leading to a higher probability of failure. High costs of transportation incurred in catering for distant markets most probably play an important role in shaping this non-linear relationship between Market Concentration and the likelihood of exit. 
Except for the segment of the scale of the variable in which the hazard of exit is a decreasing function of diversification, results with the variable Market Concentration find no correspondence with theoretical arguments on a postulated impact of geographic market diversification upon survival. However, it seems unreasonable to deny that there are high costs and benefits associated with geographic market diversification and, thus, an optimal must exist. Brüderl and Others (1992), who worked with a sample of businesses of self-employed entrepreneurs with a mean size of less than two employees, reported finding geographical diversification, operationalized in a dummy variable, significantly and negatively related to the hazard rate.

\section{CLIENT CONCENTRATION AND SALES CONCENTRATION IN BIG CLIENTS}

Small manufacturing concerns with higher concentration of sales in customers have a higher probability of failure. The coefficients of the Client Concentration and Sales Concentration in Big Clients variables in Table I are statistically highly significant in all hazard rate regression equations. Sales Concentration in Big Clients has the highest value for the zstatistic in the Cox regression equation (1a).

Findings with Client Concentration and Sales Concentration in Big Clients perfectly agree with the theoretical argument seen in the chapter on review of literature that more diversified enterprises have lower variance of earnings and, as a consequence, tend to show lower probability of failure. They are also in agreement with results from Bechetti and Sierra (2003)'s study, which revealed that share of sales to three largest customers significantly discriminated sound companies from stressed and failed ones, the latter having higher customers' concentration.

\section{$\underline{\text { SALES UNPREDICTABILITY }}$}

Small manufacturing enterprises scoring high in the scale of Sales Unpredictability tend to exit sooner. This signifies that difficulties in coping with demand shocks actually reduce the probability of surviving for the small manufacturing companies. Finding such a relationship is in perfect accordance with theoretical arguments presented in the review of literature section and empirical evidence (Becchetti and Sierra, 2003; Männasoo, 2008; Frankish and Others, 2012).

\section{ENTREPRENEUR'S RISK TOLERANCE}

This variable is one of the two that have in all hazard rate regression equations the coefficients with the highest levels of statistical significance. Owners with riskier profiles have higher probability of failure. Lack of correspondence between the monotonic linear finding reported in Table I and the inverse U-shaped pattern between risk attitudes and survival predicted by psychological research, as seen in Section 2, and empirically confirmed by Caliendo and Others (2010), calls for the task of conciliation. One explanation for this lack of correspondence may be that psychological research predicts on the basis of the complete spectrum of risk attitudes once it has studied, according to Caliendo and Others (2010), differences in risk attitudes between the groups of self-employed and regularly employed persons. Caliendo and Others (2010), themselves, may have found the inverse U-shaped relationship with survival because they worked with most of the spectrum of risk attitudes, once their sample was made up of any self-employed person. The present research interviewed only owners of well established small manufacturing enterprises, which most certainly do not include people in the lowest range of the spectrum of risk attitudes, who would be driving Caliendo and Others (2010)'s results. 
The finding reported in Table I appears to be what it really should be. It might seem to run contrary to common sense, since people use to say that those who do not take risks will not ever enjoy "a good meal". This may well be true, but it by no means warrants the conclusion that all those who invest in risky projects will get high profits from them, since, as long as risky projects are concerned, a low degree of success or even failure is the rule and high success is the exception. As a result, any study regressing degree of success upon level of risk taking should find a negative coefficient.

It is worth noting that previous results for risk-taking propensity are inconsistent. Many studies find no effect upon entrepreneurial performance (Rauch and Frese, 2007; Zhao and Others, 2010).

Last, the point should be made that, as is the case for The Machinery/Fixed Assets Ratio, controlling for Entrepreneur's Risk Tolerance importantly increases the quality of results pertaining to almost all the other individual effects. Introducing Entrepreneur's Risk Tolerance into regression equation (1a) raises the LR chi2 from 66.71 to the 119.44 reported in Table I. Astonishingly, this is nearly a doubling enhancing effect. Thus, not controlling for it may be a major source of model specification error.

\section{3-YEAR LAGGED GDP GROWTH RATE AND 1998 YEAR DUMMY}

The GDP growth rate reaches statistical significance in the hazard rate regression only in its 3-year lagged version. Its sign is negative. Farinha (2005), who also found a statistically significant and negative association between a 3-year lagged GDP Growth Rate and the hazard rate, asserted that such a result is in line with the conjecture that firms do not effectively leave the market when they get into financial distress, but only a few years later.

The variable 1998-year Dummy is the only year dummy to reach statistical significance in the hazard rate regression equations and for this reason it is the only one to be kept in the final hazard rate regressions in Table I. The direction of the relationship is positive, meaning that the year 1998 raises the probability of failure for the small firms in the risk set.

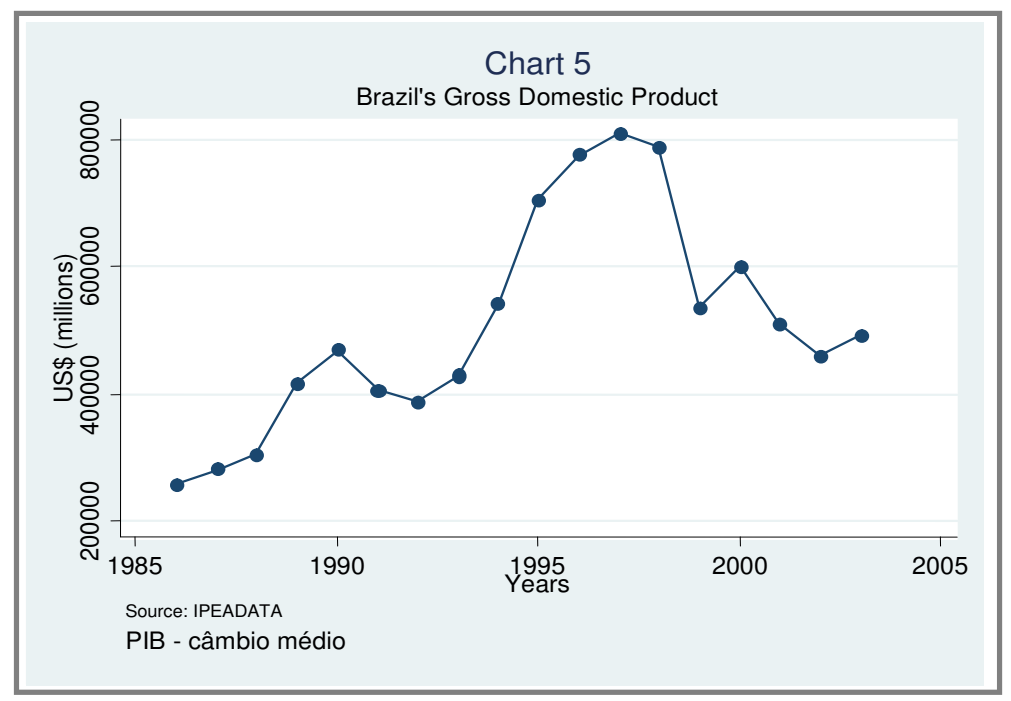

The reason the above association exists lies in the fact that in that year an economic slowdown took place in Brazil. Chart 5 shows what happened to the Brazilian Gross Domestic Product as from about the year 1998. It is widely known that such an event was the result of the 
spread of the 1997-98 Asian Financial Crisis. The impact upon the real economy might have been less drastic than the graph signalizes, since that crisis was originally a currency depreciation one, initiated in the so-called Asian Tigers. Heshmati (2001) reported finding a strong negative impact of the years 1997-98 upon the probability of survival in micro and small firms in Sweden.

The above results are in line with the arguments listed in the Section on literature review that back up the postulation of economic conditions as determinants of small business' hazard of exit. As to empirical evidence, there is conflicting findings, mainly with respect to the direction of effects, but the majority are that good economic climate impacts negatively the hazard rate and bad economic conditions impacts positively (Audretsch and Mahmood, 1995; Fotopoulos and Louri, 2000; Van Praag, 2003; Buehler and Others, 2005; Carter and Van Auken, 2006; Oh and Others, 2009; Geroski and Others, 2010; Christie and Sjoquist, 2012). Inconsistency in previous empirical findings is very high and tackling it is left for a future task.

\section{INTERACTIONS}

Only the two interactions shown in Table I are statistically significant at the level accepted as appropriate for this research. The interaction corresponding to the product of Market Concentration and Operational Cycle is negatively related to the hazard rate. This result seems to suggest that one way the small manufacturing enterprises find to counterbalance the higher risk of operating in one or few regional markets is to try to maintain or even raise sales volume by putting on offer a wider variety of manufactured goods, keeping a higher quantity of goods in stock and relaxing credit terms and collection policies so that clients are catered for at the highest level of satisfaction and respond to this with a high level of loyalty.

Chart 6 is shown only to illustrate the point that if the interaction is not controlled for the resulting fitting of Market Concentration would be very different from what it is. An ill-advised researcher might even fit a linear term for Market Concentration and come out with a significant linear association that would be consistent with the belief that concentrating marketing efforts is

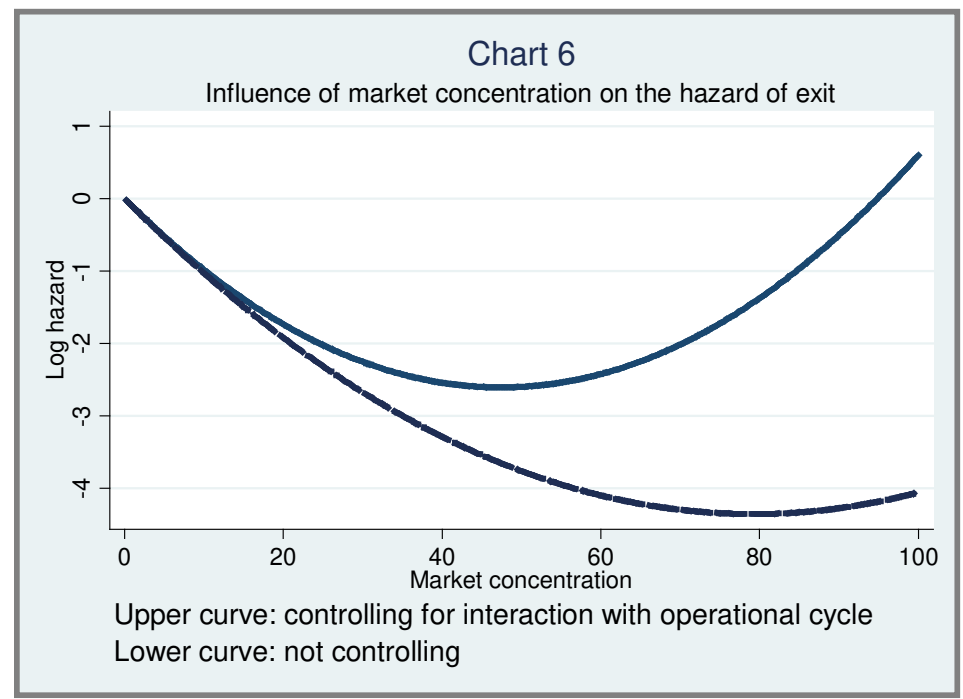

the best strategy for small enterprises.

Results with the interaction between Sales Concentration in Big Clients and The Machinery/Fixed Assets Ratio seem to be consistent with the widespread idea that big buyers are interested in buying in great quantities and at very low unit prices and that one way of qualifying 
for this kind of catering is making use of capital-intensive technologies, which are capable of mass production of good quality products at a low average unit cost. So, according to Table I, trying to guarantee sales through concentrating the marketing effort on selling to big clients is very risky, but this strategy is less of a problem when it is combined with a production strategy that invests in capital-intensive technologies.

5. CONCLUSIONS, STRENGHTS AND LIMITATIONS OF THE STUDY AND SUGGESTIONS FOR FUTURE RESEARCH AND SMALL BUSINESS DEVELOPMENT SUPPORT POLICIES

Explanatory power is astonishingly high for the survival analysis, even after consideration of the fact that statistics for measuring it are plagued by difficulties. This result defies strong opinions that failure is most elusive and difficult to explain. Statistical significance is extremely high for all covariates. This result also defies strong opinions that such studies are doomed to face inconsistency of key explanatory variables. All operationalizations of the important studied concepts seem very much to have played very well the roles expected from them.

Analyses produce evidence in favor of many postulated determinants of small business survival. Most of these determinants are, individually, combined or interacted, elements of the day-to-day operations of the enterprise, and, also in most cases, correspond to quantities that deserve to be kept under judicious control, once the corresponding level, amount or degree that benefits the enterprise the most is an optimal. These are the cases of the determinants concerning the financing strategy of the company, namely, Liquidity, operationalized by Net Working Capital, and Financial Leverage, operationalized by Total Financial Leverage and Mediumand Long-term Financial Leverage. Those characteristics are also the cases of the concepts of Working Capital, operationalized by Operational cycle, and Capital Intensity, operationalized by Automation Degree and the Machinery/Fixed Assets Ratio. Both characteristics are also the case of one of the operationalizations of Strategy, namely, Market Concentration. Sales Concentration in Big Clients, one of the operationalizations of Strategy, is an element of the day-to-day operations of the enterprise and indirectly involves an optimal in its interaction with The Machinery/Fixed Assets Ratio. Corporate Diversification, Client Concentration and Profitability, which are also operationalizations, do not involve an optimal, but are elements of the day-to-day operations of the enterprise. They are associated in a monotonic fashion with the probability of failure, being that Profitability and Corporate Diversification are negatively signed, and Client Concentration and Sales Concentration in Big Clients are positively signed. Last, the interactions, one between Market Concentration and Operational Cycle, and the other between Sales Concentration in Big Clients and The Machinery/Fixed Assets Ratio, are elements of the day-to-day operations of the enterprise and involve an optimal, once they have to be taken into account in conjunction with the single variables and at least one of them in each interaction involves an optimal on its own. In all these cases the owner-manager may exert some control over the determinants of his/her enterprise's survival prospects, at least in theory.

Other postulated determinants of small business survival receive strong support from evidence produced by the analyses, but they do not have the above nature. Business Risk, operationalized by Sales Unpredictability, and Economic Conditions, operationalized by The 3year-lagged GDP Growth Rate and The 1998 Year Dummy are not elements of the day-to-day operations of the enterprise, nor involve optimals. Sales Unpredictability and The 1998 Year Dummy are positively signed, whereas The 3-year-lagged GDP Growth Rate is negatively signed, meaning that good environmental conditions diminish failure probability and bad 
environmental conditions raise it. In none of these cases the owner-manager may exert any control over the determinants of his/her enterprise's survival prospects, for sure.

The last concept receiving strong support from the evidence brought about by the analyses in this study, namely, Characteristics of the Entrepreneur, operationalized by Entrepreneur's Risk Tolerance, has nothing to do with the two kinds of nature depicted above. Entrepreneur's Risk Tolerance is positively signed, meaning that owner/managers with riskier profiles have higher probability of failure. The extent to which the owner/manager can exert a control over this determinant of his/her firm's failure probability is open to question and so it seems to be the extent to which he/she can exert control over himself/herself.

Overall, the conclusion is that the main findings of this research effort suggest that the survival chances of the small manufacturing enterprises lie much within their own control. However, it was not possible to conclude in the specific case of this small firm sample whether the successful choices were conscious or the corresponding enterprises were selected in the way predicted by the organizational ecology approach.

Some selected specific conclusions are as follows. The curve representing the effect of working capital perfectly mirrors the classical curves of total costs of the models of economic order quantity and economic production quantity. This is suggestive that the same decisions that impact the costs of investing in working capital have an effect upon the probability of exit. The curve representing the effect of capital intensity also has a minimum, but the $U$ shape is perfectly symmetrical. A second important identified effect of fixed assets concerns their either higher or lower capacity of playing the role of collateral. Empirical findings concerning the market and competitive strategies indicate that, even for small owners, who do not have much to invest, the old rule of thumb that the eggs should be carried in many baskets, to lose the least in case of a fall, is still a very pertinent finance principle.

Of course, there are limitations to this study. Overcoming them is then the first suggestion for future enquiries. Increasing the size of the sample, adding more industry sectors and expanding geographical coverage would all benefit future attempts to replicate this research. This research has strengths that may as well serve as guidance for future investigations. It has explored apparently successfully some new avenues that may yield good results in research on the same areas of enquiry or related ones. For example, the use of many non-linear specifications and following modeling for the time to event data typically encountered in health related studies have proved to be invaluable in this work. Being specific, it may pay future studies to use binomials with powers either higher or lower than the conventional unity and square ones to obtain a better fit in the regression equations. In this research, this choice has enhanced in the survival analyses not only the fit for the factor being dealt with but also the fits for all the others in the same specification. Such drastic changes in methodology may even ease theory building in the field.

As to recommendations for policy making for small business development, small business support initiatives and small enterprises' decision-making, it is very fortunate that the research found that the majority of the main survival determinants are elements of the small firms' strategic choices, because, it is believed, if they were mostly either industry- or economy-level factors, little could be done to mitigate these concerns' weaknesses. Official support to small business development should, then, be focused on the provision of financial and managerial assistance. However, as many determinants of survival are related to the strategic choice in a complex manner, this certainly calls for human capital development before an adviser may be able to give orientation on this matter to small business owners. Small business owners also should seek first such a qualification before trying to make use of the results from this research by themselves. 


\section{REFERENCES}

Audretsch, David B. (1991), New firm survival and the technological regime, The Review of Economics and Statistics, 73: 441-450.

Audretsch, David B. and Talat Mahmood (1995), New Firm Survival: New Results Using a Hazard Function, Review of Economics and Statistics 97: 97-103.

Barbosa, Evaldo Guimarães (2009), Common Determinants of the Firm's Capital Structure and Business Survival - The Case of Very Small Enterprises of Traditional Manufacturing Sectors in Brazil, Createspace - An Amazon company, Charleston, SC, USA.

Barton, Sidney L. and Charles H. Matthews (1989), Small firm financing: Implications from a strategic management perspective, Journal of Small Business Management, 27(1): 1-7.

Bates, Timothy (1995), A Comparison of Franchise and Independent Small Business Survival Rates, Small Business Economics 7(5): 377-88. October.

Becchetti, Leonardo and Jaime Sierra (2003), Bankruptcy risk and productive efficiency in manufacturing firms, Journal of Banking \& Finance 27:2099-2120.

Bellone, Flora, Patrick Musso, Lionel Nesta and Michel Quéré (2006), Productivity and Market Selection of French Manufacturing Firms in the Nineties, Revue de l'OFCE 97(BIS): 319-49. June.

Binks, Martin (1979), Finance for expansion in the small firm, Lloyds Bank Review 134, 33-45.

Bławat, Franciszek, Piotr Dominiak and Jerzy Ossowski (2001), Analysis of factors determining the survival capacity of small and medium-sized enterprises, Statistics in Transition 5(1): 93124. March.

Bottazzi, Giulio, Marco Grazzi, Angelo Secchi, and Federico Tamagni (2011), Financial and economic determinants of firm default, Journal of Evolutionary Economics 21(3): 373-406. August.

Brophy, David J. and Joel M. Shulman (1992), A finance perspective on entrepreneurship research, Entrepreneurship: Theory \& Practice 16(3): 61-71.

Brüderl, Josef, Peter Preisendorfer and Rolf Ziegler (1992), Survival Chances of Newly Founded Business Organizations, American Sociological Review 57(2):227-42.

Buehler, Stefan, Christian Kaiser and Franz Jaeger (2005), Competition Policy and Exit Rates: Evidence from Switzerland, B.E. Journal of Economic Analysis and Policy (Contributions in Economic Analysis \& Policy) (DOI: 10.2202/1538-0645.1444) 4(1): Article 15. November.

Bunn, Philip and Victoria Redwood (2003), Company accounts based modelling of business failures and the implications for financial stability, Working Paper no. 210, Bank of England.

Caliendo, M., F. Fossen, and A. Kritikos (2010), The impact of risk attitudes on entrepreneurial survival, Journal of Economic Behavior and Organization 76(1): 45-63.

Carter, Richard and Howard Van Auken (2006), Small Firm Bankruptcy, Journal of Small Business Management, 44, no. 4 (October): 493-512.

Chell, E., J. Harworth, and S. Brearley (1991), The search for entrepreneurial traits, In E. Chell, J. Harworth, and S. Brearley (Eds.), The Entrepreneurial Personality: Concepts, Cases and Categories, Routledge Small Business Series, pp. 29-53, London: Thomson Learning.

Christie, Tamoya and David L. Sjoquist (2012), New Business Survival in Georgia: Exploring the Determinants of Survival Using Regional Level Data, Growth and Change 43(1):110-42. (March).

Cox, D. R. (1972), Regression Models and Life-Tables, Journal of Royal Statistical Society, Series B, 34, 187-220.

Cox, D. R. (1975), Partial likelihood, Biometrica 62, 269-276.

De Jong, Abe and Ronald van Dijk (2007), Determinants of leverage and agency problems: A regression approach with survey data, European Journal of Finance 13(6): 565-93, doi:10.1080/13518470701198734. 
De Mel, Suresh, David McKenzie and Christopher Woodruff (2010), Who Are the Microenterprise Owners? Evidence from Sri Lanka on Tokman v. de Soto, in International Differences in Entrepreneurship, Lerner and Schoar, eds., University of Chicago Press.

De Mel, Suresh, David McKenzie and Christopher Woodruff (2009), Innovative Firms or Innovative Owners? Determinants of Innovation in Micro, Small, and Medium Enterprises, World Bank Policy Research Working Paper No. 4934.

Doms, M., T. Dunne, and M. J. Roberts (1995), The Role of Technology Use in the Survival and Growth of Manufacturing Plants, International Journal of Industrial Organization 13: 523-42.

Everett, Jim and John Watson (1998), Small Business Failure and External Risk Factors, Small Busines Economics 11(4): 371-90.

Farinha, Luisa A. (2005), The Survival of New Firms: Impact of Idiosyncratic and Environmental Factors, Financial Stability Report 2005, Banco de Portugal.

Fernandes, Ana M. and Caroline Paunov (2015), The Risks of Innovation: Are Innovating Firms Less Likely to Die?, The Review of Economics and Statistics 97(3):638-53. July.

Fotopoulos, Giorgios and Helen Louri (2000), Determinants of Hazard Confronting New Entry: Does Financial Structure Matter?, Review of Industrial Organization 17: 285-300.

Frank, Murray Z. and Vidhan K Goyal (2008), Trade-off and Pecking Order Theories of Debt, in Espen Eckbo (editor) Handbook of Corporate Finance: Empirical Corporate Finance 2: 135202 (Elsevier Science/North-Holland).

Frankish, Julian S., Richards G. Roberts and David J. Storey (2012), Do entrepreneurs really learn? Or do they just tell us that they do?, Industrial and Corporate Change pp:1-34, doi: 10.1093/icc/dts016. June.

Frazer, Garth (2005), Which Firms Die? A Look at Manufacturing Firm Exit in Ghana, Economic development and cultural change, Chicago, Ill : Univ. of Chicago Press, ISSN 0013-0079, ZDB-ID 16883. - Vol. 53, 3, p. 585-618.

Fredland, E. J. and C.E. Morris (1976), A Cross Section Analysis of Small Business Failure, American Journal of Small Business 1(1): 7-18. July.

Geroski, Paul A., José Mata and Pedro Portugal (2010), Founding Conditions and The Survival of New Firms, Strategic Management Journal 31(5): 510-29. (May)

Grossi, Luigi and Giorgio Gozzi (2006), Firm turnover and duration of new firms in italian mechanical sector: evidence in the period 1997-2002, in Mutamenti nella geografia dell'economia italiana (Ed. C. Filippucci), pp. 331-352, Milano, FrancoAngeli.

Ha, Nguyen Minh (2013), The Effect of Firm's Growth on Firm Survival in Vietnam, International Business Research 6(5): 142-56.

Harris, R. and Q.C. Li (2010), Export-market dynamics and the probability of firm closure: evidence for the United Kingdom, Scottish Journal of Political Economy 57(2):145-68.

Heshmati A. (2001), On the Growth of Micro and Small Firms: Evidence from Sweden, Small Business Economics 17(3): 213-228. November.

Hosmer, David W. Jr. and Stanley Lemeshow (1999), Applied Survival Analysis - Regression Modeling of Time to Event Data, John Wiley \& Sons, New York, NY.

Huynh, Kim P., Robert J. Petrunia and Marcel C. Voia (2010), The impact of initial financial state on firm duration across entry cohorts, The Journal of Industrial Economics 58(3):661-89. September.

Kang, Jae-Won, Almas Heshmati and Gyong-Gyu Choi (2008), , Effect of credit guarantee policy on survival and performance of SMEs in Republic of Korea, Small Business Economics, 31(4): 445-62. December.

Konings, Jozef and Ana Xavier (2002), Firm Growth and Survival in a Transition Country: Micro Evidence from Slovenia, Working paper, LICOS - Centre for Transition Economics, Katholieke Universiteit Leuven, Leuven, Belgium.

Long, J. Scott (1997), Regression Models for Categorical and Limited Dependent Variables, Sage Publications, Thousand Oaks, California. 
López-García, Paloma and Sergio Puente (2006), Business Demography in Spain: Determinants of Firm Survival, Paper presented at the refereed 2006 Comparative Analysis of Enterprise Data Conference (Chicago), Federal Reserve Bank of Atlanta.

Männasoo, Kadri (2008), Patterns of Firm Survival in Estonia, Eastern European Economics 46(4): 27-42.

Mata, José and Pedro Portugal (2002), The Survival of New Domestic and Foreign owned Firms, Strategic Managemente Journal 23(4): 323-43. April.

Mengistae, Taye (2006), Competition and Entrepreneurs' Human Capital in Small Business Longevity and Growth, Journal of Development Studies 42(5): 812-36. (July).

Norušis, Marija J. (1992), SPSS for Windows: Base System User's Guide, Release 5.0 (SPSS Inc., Chicago, Ill.).

Oh, Inha, Almas Heshmati, Chulwoo Baek and Jeong-Dong Lee (2009), Comparative Analysis of Plant Dynamics by Size: Korean Manufacturing, The Japanese Economic Review 60(4): 512-38. December.

Pakes, Ariel and Richard Ericson (1998), Empirical Implications of Alternative Models of Firm Dynamics, Journal of Economic Theory 79(1): 1-46.

Pérez, Silviano Esteve, Amparo Sanchis Llopis and Juan Alberto Sanchis Llopis (2004), The Determinants of Survival of Spanish Manufacturing Firms, Review of Industrial Organization 25(3):251-73. (November).

Rauch, A. and M. Frese (2007), Let's put the person back into entrepreneurship research: A metaanalysis on the relationship between business owners' personality traits, business creation, and success, European Journal of Work and Organizational Psychology 16: 353-85.

Romano, Claudio A., George A. Tanewski and Kosmas X. Smyrnios(2000), Capital structure decision-making: a model for family business, Journal of Business Venturing 16(3): 285-310.

Shiferaw, Admasu (2009), Survival of private sector manufacturing establishments in Africa: The role of productivity and ownership, World Development 37(3): 572-84. (March).

Söderbom, Måns, Francis Teal and Alan Harding (2006), The Determinants of Survival among African Manufacturing Firms, Economic Development and Cultural Change 54(3):533-55.

Taymaz, Erol and Sule Ozler (2007), Foreign Ownership, Competition, and Survival Dynamics, Review of Industrial Organization 31(1): 23-42. August.

Van Horne, James C. (1977), Financial Management and Policy, Prentice-Hall Inc., New Jersey, USA.

Van Praag, C. Mirjam (2003), Business Survival and Success of Young Small Business Owners, Small Business Economics 21(1): 1-27. August.

Van Praag, Mirjam, Gerrit de Wit and Niels Bosma (2005), Initial capital constraints hinder entrepreneurial venture performance, The Journal of Private Equity 9(1): 36-44. Winter.

Verheul, Ingrid and Roy Thurik (2001), Start-up Capital: “Does Gender Matter?”, Small Business Economics 16(4): 329-46.

Wagenvoort, Rien and Christopher Hurst (1999), How well do European loan markets work? Some insights from the financial structure of SMEs in three countries, European Investment Bank Papers 4(2): 64-86.

$\mathrm{Wu}$, Chunchi and Allan Young (2002), Critical operating problems and survival rates in small firms: a look at small business institute clients, Journal of Developmental Entrepreneurship 7(1): $1-23$.

Zhao, Hao, Scott E. Seibert and G. T. Lumpkin (2010), The relationship of personality to entrepreneurial intentions and performance: A meta-analytic review, Journal of Management 36(2): 381-404. March. 
DETERMINANTS OF SMALL BUSINESS SURVIVAL

APPENDICES:

Appendix I Survival Variables Summary Statistics

\begin{tabular}{c|c|c|c|c}
\hline Variables & Mean & $\begin{array}{c}\text { Standard } \\
\text { Deviation }\end{array}$ & Minimum & Maximum \\
\hline Duration (1) & $2,455.62$ & $1,749.86$ & 21.00 & $4,748.00$ \\
\hline Exit(2) & 0.75 & 0.43 & 0.00 & 1.00 \\
\hline Net working capital (3) & 0.49 & 0.27 & -0.24 & 1.00 \\
\hline Total financial leverage (4) & 0.31 & 0.20 & 0.00 & 0.90 \\
\hline Medium- and long-term financial leverage(5) & 0.06 & 0.07 & 0.00 & 0.35 \\
\hline Profitability (6) & 3.33 & 1.59 & 0.00 & 5.00 \\
\hline Operational cycle (7) & 98.70 & 49.27 & 24.00 & 270.00 \\
\hline Machinery/fixed assets ratio (8) & 0.58 & 0.30 & 0.00 & 1.00 \\
\hline Automation degree (9) & 3.16 & 0.99 & 1.00 & 5.00 \\
\hline Corporate diversification(10) & 8.30 & 19.70 & 0.00 & 80.00 \\
\hline Market concentration (11) & 49.55 & 29.39 & 3.86 & 100.00 \\
\hline Client concentration (12) & 59.34 & 27.96 & 6.67 & 100.00 \\
\hline Sales concentration in big clients (13) & 40.98 & 38.37 & 0.00 & 100.00 \\
\hline Sales unpredictability (14) & 2.77 & 2.74 & 0.00 & 6.00 \\
\hline Entrepreneur's risk tolerance (15) & 2.51 & 1.26 & 1.00 & 5.00 \\
\hline 3-year-lagged GDP growth rate(16) & 2.24 & 2.75 & -4.30 & 5.90 \\
\hline 1998 year dummy (17) & 0.11 & 0.32 & 0.00 & 1.00 \\
\hline
\end{tabular}

\begin{tabular}{c|c|c|c|c|c}
\hline \multirow{2}{*}{ Variables } & \multicolumn{3}{|c|}{ Fractiles } & \multirow{2}{*}{ Kurtosis $^{*}$} & \multirow{2}{*}{ Skewness } \\
\cline { 2 - 4 } & 0.10 & 0.50 & 0.90 & & \\
\hline Duration (1) & 82.40 & $1,980.00$ & $4,748.00$ & -1.55 & 0.16 \\
\hline Exit(2) & 0.00 & 1.00 & 1.00 & -0.56 & -1.21 \\
\hline Net working capital (3) & 0.14 & 0.56 & 0.81 & 0.75 & -0.80 \\
\hline Total financial leverage (4) & 0.10 & 0.28 & 0.58 & 0.76 & 0.84 \\
\hline Medium- and long-term financial leverage(5) & 0.00 & 0.03 & 0.16 & 2.87 & 1.61 \\
\hline Profitability (6) & 0.20 & 3.00 & 5.00 & -0.40 & -0.69 \\
\hline Operational cycle (7) & 51.20 & 85.00 & 179.60 & 2.39 & 1.51 \\
\hline Machinery/fixed assets ratio (8) & 0.11 & 0.60 & 0.92 & -1.05 & -0.39 \\
\hline Automation degree (9) & 2.00 & 3.00 & 4.80 & -0.06 & -0.02 \\
\hline Corporate diversification(10) & 0.00 & 0.00 & 35.00 & 6.04 & 2.60 \\
\hline Market concentration (11) & 8.87 & 46.86 & 97.29 & -1.07 & 0.21 \\
\hline Client concentration (12) & 24.94 & 51.00 & 100.00 & -1.19 & 0.32 \\
\hline Sales concentration in big clients (13) & 0.00 & 33.00 & 100.00 & -1.48 & 0.31 \\
\hline Sales unpredictability (14) & 0.00 & 1.00 & 6.00 & -1.85 & 0.24 \\
\hline Entrepreneur's risk tolerance (15) & 1.00 & 3.00 & 4.80 & -0.63 & 0.39 \\
\hline 3-year-lagged GDP growth rate(16) & -3.54 & 2.70 & 5.90 & 0.97 & -1.09 \\
\hline 1998 year dummy (17) & 0.00 & 0.00 & 1.00 & 4.28 & 2.48 \\
\hline Obs.: 1) Number or cases: 61;2) Valus
\end{tabular}

Obs.: 1) Number of cases: 61 ; 2) Values in currency are in thousands and in 1992 prices, and the mean and year-end exchange rates for that year were $\operatorname{Cr} \$ 4,516.74$ and $\operatorname{Cr} \$ 11,213.12$ per US\$ Dollar, respectively; 3) *According to Norušis (1992, p.167), in the SPSS the value of kurtosis for the normal distribution is, differently from many textbooks in statistics, 0 and not 3 . 
EVALDO GUIMARÃES BARBOSA

Appendix II Survival Variables Intercorrelation Matrix

\begin{tabular}{c|c|c|c|c|c|c|c|c}
\hline & $(1)$ & $(2)$ & $(3)$ & $(4)$ & $(5)$ & $(6)$ & $(7)$ & $(8)$ \\
\hline Duration (1) & - & & & & & & & \\
\hline Exit (2) & -0.74 & - & & & & & & \\
\hline Net working capital (3) & 0.21 & -0.02 & - & & & & & \\
\hline Total financial leverage (4) & -0.06 & -0.02 & -0.62 & - & & & & \\
\hline $\begin{array}{c}\text { Medium- and long-term financial } \\
\text { leverage(5) }\end{array}$ & -0.23 & 0.16 & -0.37 & 0.38 & - & & & \\
\hline Profitability (6) & 0.21 & -0.20 & 0.05 & 0.04 & -0.15 & - & & \\
\hline Operational cycle (7) & 0.03 & 0.20 & 0.01 & 0.04 & 0.17 & 0.09 & - & \\
\hline Machinery/fixed assets ratio (8) & -0.08 & -0.00 & -0.05 & 0.09 & 0.16 & 0.11 & -0.07 & - \\
\hline Automation degree (9) & -0.04 & -0.06 & -0.15 & 0.33 & 0.22 & 0.28 & -0.14 & 0.01 \\
\hline Corporate diversification (10) & 0.11 & 0.06 & -0.08 & 0.09 & 0.08 & 0.02 & 0.12 & 0.13 \\
\hline Market concentration (11) & -0.01 & -0.02 & -0.05 & -0.15 & -0.05 & 0.20 & 0.00 & -0.13 \\
\hline Client concentration (12) & 0.07 & 0.02 & 0.14 & -0.08 & -0.07 & 0.08 & -0.01 & -0.01 \\
\hline Sales concentration in big clients (13) & -0.23 & 0.13 & 0.23 & -0.02 & 0.03 & -0.06 & 0.00 & -0.06 \\
\hline Sales unpredictability (14) & -0.23 & 0.08 & 0.02 & -0.18 & -0.09 & -0.19 & -0.12 & -0.01 \\
\hline Entrepreneur's risk tolerance (15) & -0.26 & 0.17 & -0.18 & 0.25 & 0.12 & 0.00 & -0.15 & 0.18 \\
\hline 3-year-lagged GDP growth rate(16) & 0.15 & -0.10 & -0.18 & 0.18 & -0.00 & 0.01 & 0.06 & -0.25 \\
\hline 1998 year dummy (17) & -0.13 & 0.21 & -0.17 & 0.31 & -0.02 & 0.25 & 0.02 & -0.20 \\
\hline
\end{tabular}

\begin{tabular}{c|c|c|c|c|c|c|c|c}
\hline & $(9)$ & $(10)$ & $(11)$ & $(12)$ & $(13)$ & $(14)$ & $(15)$ & $(16)$ \\
\hline Duration (1) & & & & & & & & \\
\hline Exit(2) & & & & & & & & \\
\hline Net working capital (3) & & & & & & & & \\
\hline Total financial leverage (4) & & & & & & & & \\
\hline $\begin{array}{c}\text { Medium- and long-term financial } \\
\text { leverage (5) }\end{array}$ & & & & & & & & \\
\hline Profitability (6) & & & & & & & & \\
\hline Operational cycle (7) & & & & & & & & \\
\hline Machinery/fixed assets ratio (8) & & & & & & & & \\
\hline Automation degree (9) & - & & & & & & & \\
\hline Corporate diversification (10) & -0.05 & - & & & & & & \\
\hline Market concentration (11) & 0.01 & -0.13 & - & & & & & \\
\hline Client concentration (12) & -0.10 & -0.03 & 0.20 & - & & & & \\
\hline Sales concentration in big clients (13) & 0.16 & -0.13 & -0.08 & 0.05 & - & & & \\
\hline Sales unpredictability (14) & -0.44 & -0.16 & 0.20 & 0.02 & -0.16 & - & & \\
\hline Entrepreneur's risk tolerance (15) & 0.05 & -0.03 & -0.09 & -0.10 & -0.15 & -0.06 & - & \\
\hline 3-year-lagged GDP growth rate (16) & -0.06 & -0.06 & -0.10 & -0.17 & 0.02 & 0.04 & -0.02 & - \\
\hline 1998 year dummy (17) & 0.10 & 0.10 & 0.00 & -0.34 & -0.07 & -0.01 & 0.14 & 0.48 \\
\hline
\end{tabular}

Obs.: 1) Number of cases: 61 ; 2) Coefficients in absolute values higher than 0.20 are statistically significant at the $5 \%$ level, higher than 0.30 at the $1 \%$, and higher than 0.40 at the $0.1 \%$, in one-tail test. 